\title{
The dampening effect of iceberg orders on small traders' welfare
}

\section{A real options perspective}

\author{
Laura Delaney $^{1}$ D Polina Kovaleva ${ }^{1}$
}

Received: 13 March 2017 / Accepted: 31 July 2017 / Published online: 10 August 2017

(C) The Author(s) 2017. This article is an open access publication

\begin{abstract}
Iceberg orders, which allow traders to hide a portion of their order size, have become prevalent in many electronic limit order markets. This paper investigates, via a real options analysis, whether small traders, who have no use for submitting iceberg orders, are better off submitting their orders to fully transparent markets which have low depth, or to more liquid markets which do permit the placement of iceberg orders by large traders. Surprisingly, we find that in the context of our model, small traders are better off submitting to fully transparent markets in spite of them being less liquid.
\end{abstract}

Keywords Optimal timing $\cdot$ Iceberg orders $\cdot$ Limit order book $\cdot$ Welfare

\section{JEL Classification C44 · G11}

\section{Introduction}

Iceberg orders which are a particular type of limit order permitted by a large number of exchanges (for example, among others, the London Stock Exchange (with its orderdriven services SETS, SETSmm, and IOB), Euronext, the Toronto Stock Exchange, the Australian Stock Exchange, and the NYSE). The investors submitting such orders to the limit order book (LOB) specify the total quantity they want to buy or sell at a particular price and this is recorded in the book according to its price and time priority. However, only a fraction of the total order size is visibly displayed to the other market participants. The quantity displayed is called a peak and when the full size of the peak has been executed against incoming orders of the opposite sign, the peak quantity is

\footnotetext{
$\bowtie$ Laura Delaney

laura.delaney.1@city.ac.uk

1 Department of Economics, City University, Northampton Square, London EC1V 0HB, UK
} 
automatically renewed and positioned behind other visible limit orders at the same price. As the hidden depth is gradually revealed, investors who carefully monitor the order flow in the LOB are expected to detect the presence of hidden depth. However, even when hidden depth is detected, the investor cannot determine the iceberg order's full size, but he can form increasingly precise expectations as to its size as more and more peaks are executed and new ones displayed.

The use of iceberg orders in limit order markets has become prevalent in recent years, as documented by empirical evidence. For example, Tuttle (2006) reports that hidden depth accounts for $22 \%$ of the inside depth in Nasdaq 100 stocks, while DeWinne and D'Hondt (2007) find that it accounts for $45 \%$ of the total depth available at the best five quotes, on average, for stocks constituting the CAC 40 index on Euronext-Paris. Bessembinder et al. (2009) also report that, out of a sample of one hundred stocks traded on Euronext-Paris, iceberg orders account for approximately $44 \%$ of order volume, and Frey and Sandås (2009) show that on Xetra, while the iceberg orders' share of all non-marketable orders submitted is only about $9 \%$, these orders are, on average, between 12 and 20 times larger than usual limit orders.

The natural question to ask, therefore, is what are the costs and benefits of iceberg orders to financial markets and their participants? The general consensus appears to be that the attractiveness to traders of using iceberg orders is that they help to manage exposure risk ${ }^{1}$ (see Harris 1996; Aitken et al. 2001; DeWinne and D'Hondt 2007; Frey and Sandås 2009; Bessembinder et al. 2009). Anand and Weaver (2004) show that by introducing iceberg orders on the Toronto Stock Exchange in 2002, the total depth of the LOB increased significantly. Consistent with this result, Moinas (2010) shows that larger market depth induces liquidity demanders to submit larger orders, which increases their expected utility, and liquidity suppliers can use iceberg orders to decrease the informational impact of their large orders. Consequently, both liquidity demanders and liquidity suppliers have higher welfare when trading in iceberg markets. Buti and Rindi (2013) develop a model which also shows that traders who can use iceberg orders have greater total welfare.

While the above studies all highlight the benefits of iceberg orders, they are, however, all focussed on traders for which it is plausible to use such orders; i.e., large traders. However, to the best of our knowledge, there is no analysis on the effects of iceberg orders on small traders who have no use for submitting iceberg orders and, hence, do not benefit from iceberg orders in terms of exposure risk management. Regulators are concerned about the effects of opaque markets on the welfare of market participants as a whole. In particular, they are concerned that opaque markets may affect the distribution of welfare between small and large traders, as opaque markets are primarily used by the latter (Buti et al. 2017). The reason is that large traders will submit iceberg orders on exchanges which permit their use, and thereby the transparent markets will suffer in terms of liquidity provision which will affect the welfare of small

\footnotetext{
1 Exposure risk is caused by the signal that an order gives to other market participants which helps them to infer the investor's motive and/or price impact of his trade. This could induce front-running which is the attempt by other market participants to win the order flow by marginally outstripping the price of a large order and, as a result, decrease the probability of full execution of a large limit order that was placed earlier on the same side of the book.
} 
traders. Therefore, it seems sensible to suggest that small traders would be better off submitting their orders to markets which permit the use of hidden depth. In this paper we address this issue by determining the welfare of a small trader who submits full orders only to a market which permits the use of iceberg orders. We then determine the welfare of this trader from submitting the same orders to a fully transparent market, and we find the surprising result that, while liquidity may be lower in the transparent market, their total welfare is greatly reduced if they migrate to the market with hidden depth.

The trader has an amount of capital which he wishes to use for investing in some stock. He starts to monitor the order flow of the stock in the LOB and at this stage he is interested in two things; (i) whether there is enough hidden depth in the LOB at a particular ask price of his choosing for him to be able to execute his full order at that price, and (ii) whether the demand for the stock is likely to increase sufficiently for him to be able to sell his full inventory at a higher price at some future time. He monitors the order flow in the LOB at the prices he wishes to buy and sell the stock to infer the likelihood of (i) and (ii). These likelihoods are updated in a Bayesian way every time a new order enters the LOB at the relevant prices. He invests in the stock once he is sufficiently convinced that the order will be executed and, importantly, once he is sufficiently convinced that he will be able to sell the entire order at a higher price at some time in the future. Once he invests, he continues to monitor the order flow at the sell price to determine the best time to submit his sell order such that the profit from the trade is maximised. In particular, this means that he is looking for the time at which the likelihood that his sell order will be fully executed at his preferred sell price is highest. This optimal investment timing approach has been well-developed in the corporate finance literature (see, for example, Flor and Hansen 2013; Gutierrez and Ruiz-Aliseda 2011) but, to the best of our knowledge, it is the first application of the approach in the iceberg order literature.

Our model differs from other theoretical models on LOBs and iceberg orders (see, for example, Moinas 2010; Boulatov and George 2013; Buti and Rindi 2013) in that those models are typically concerned with the traders' decisions over what type of order to submit and the optimal price, peak and/or order size. By contrast, we take the prices and quantities submitted as exogeneous parameters because we want to determine how a trade executed in a fully transparent market compares, in terms of welfare, with that same trade executed in a market with possible iceberg orders. If we were to optimise over prices or quantities, we would likely get different optimal values depending on the features of the different markets, implying that the trades would be different. For this reason, our optimal submission strategy is then one of timing; in particular, we solve two optimal stopping problems conditional on the possibility that there can be hidden depth in the LOB at the prices the investor wishes to trade at. The optimal buy strategy is influenced by the option to sell and, therefore, we must solve for the optimal time to buy using backward induction. First we solve for the optimal time to sell the stock that has been purchased and secondly we solve for the optimal time to buy conditional on the sell strategy. Our model is then adapted to determine the optimal timing strategies in the fully transparent case.

The set-up of our model in terms of information flow and hidden depth detection is consistent with empirical evidence on how hidden depth is detected from DeWinne 
and D'Hondt (2007) and Frey and Sandås (2009). Technically, it is closely related the models of information flow in Thijssen et al. (2004) and Delaney and Thijssen (2015). The former paper is concerned with a capital budgeting decision and focuses on a stand-alone option, while the latter considers how the exercise strategy of some investment option is influenced by the option to voluntarily disclose the investment return at some future date. While this paper is similar to Delaney and Thijssen (2015) in the sense that they are both compound option problems, in the latter paper, the decision variable is the same for both inter-related options whereas in this paper there is a separate decision variable for the buy and sell strategies; one representing the likely presence of hidden depth at a particular price, and one representing the likely market demand for the asset in the future. This implies that the approach to solving for the optimisation problems in this paper differs to quite a large extent to the approach needed in Delaney and Thijssen (2015). In particular, we need to consider the fact that the two variables in this paper must not be totally independent from each other, which adds another dimension to the optimisation approach which is absent in other models.

Next we determine the trader's expected total welfare from entering into the round trip trade and adhering to the optimal strategies derived. We also determine his welfare from submitting his orders to fully transparent markets where there is no hidden depth. In this market, depth is lower, but surprisingly, his welfare from trading in the transparent market is significantly higher than his welfare in the iceberg market. The result arises because, in the context of our model, the absence of any possibility of hidden depth means that the orders will only be submitted when the traders are certain of their execution and, hence, the expected payoff is higher than in the hidden depth case. Moreover, in the hidden depth case, the trader risks having his sell order filled at a lower price per share than he bought it at, whereas in the fully transparent case, he does not face such a risk. Therefore, the conclusion is that traders for whom it is not appropriate to use iceberg orders should send their orders to transparent markets in spite of the fact that they are less liquid than markets permitting iceberg order submission.

The remainder of this paper is organized as follows. The general framework of our model is described in the next section. In Sect. 3 we solve for the optimal buy and sell order placement times in the hidden depth and fully transparent cases. In Sect. 4 we conduct our welfare analysis and in Sect. 5 we give some concluding remarks. All proofs are placed in the "Appendix".

\section{The model}

\subsection{General framework}

Consider a double auction market that operates through an electronic trading system, in which orders are recorded in a limit order book (LOB) but full volume is not known to the marketplace. Hidden liquidity is generated by iceberg orders. A risk-neutral investor intends to trade in this market and conceives a round-trip trade using market 
orders only ${ }^{2}$ : buy low-sell high. His problem is to find the optimal time at which to buy and subsequently sell the stock so that his profit from the trade is maximised.

The investor starts to monitor the LOB at some time $\tau_{0}=0$ where time is continuous. He has some fixed amount of capital which he wishes to invest in a particular stock at a price $A$ per share, and which he will try to sell off at some future date for a profit; i.e., at some unit price $B^{H}$ such that $B^{H}>A .{ }^{3}$ I denote by $Q$ the number of shares he can purchase with his capital at a unit price $A$; i.e., $Q=$ capital $/ A$.

In a LOB which permits hidden depth, the total net demand at a given price $j$ is comprised of limit orders that are visible and which all market participants can observe, denoted $v_{\tau}^{j}$, and a hidden component of depth which is not observable, denoted $h_{\tau}^{j}$. Total net demand is thus $v_{\tau}^{j}+h_{\tau}^{j}$. Every time a new order is submitted to the book at $j$, the total net demand at $j$ is updated.

Buy and sell orders for the asset enter the book at random points in time. The dynamics of order arrival are governed by a Poisson process with parameter $\lambda$, and this is the same for prices $A$ and $B^{H}{ }^{4}$ Thus, the probability that a new order to buy or sell one more share of the asset enters the book at price $j$ within an infinitesimal time interval $d t$ is $\lambda d t$.

At every instant $\tau$, the investor monitors the visible net demand in the book at the prices he wants to transact at; i.e., $\mathrm{v}_{\tau}^{A}$ if at time $\tau$ he is waiting to buy, and $\mathrm{v}_{\tau}^{B^{H}}$ if at time $\tau$ he is waiting to sell. He does in fact also monitor $\mathrm{v}_{\tau}^{B^{H}}$ if at time $\tau$ he is waiting to buy, but we return to this point in a later section. While he can only observe the visible portion of net demand, he knows that there may be more hidden depth available in the book, but he does not know how much. That is, he does not know $\mathrm{h}_{\tau}^{j}$, but he knows it is not necessarily zero.

The investor infers the state of the order; i.e., whether it has hidden depth or not, correctly with probability $\theta \in(0.5,1)$. Hence, $\theta$ can be thought of as a measure for the reliability of the order flow as a signal of hidden depth.

The signals are modeled as binomially distributed random variables with parameter $\theta$, and are explained as follows: when he is waiting to submit an order, the investor examines the visible portion net demand at the price he is wanting to trade at each instant. These $\mathrm{v}_{\tau}^{j}$ orders that the investor observes sitting in the LOB could be owing to (i) full orders that are placed and have never had any hidden depth associated with them, denoted as $\mathrm{v}_{\tau}^{j f}$, or (ii) the peak (visible) part of an iceberg order, denoted as $\mathrm{v}_{\tau}^{j i}$.

\footnotetext{
2 The assumption of submitting only market orders is made for analytical tractability. The reasoning is that the point of the model is that hidden depth affects the likelihood of order execution, and this point this is true for limit order submissions also. Hence, assuming limit order submission would only complicate the analysis by adding extra discounting without altering any of the results on hidden depth which assuming market orders will generate anyway. Moreover, the plausibility of the assumption is supported by empirical evidence from DeWinne and D’Hondt (2007) and Frey and Sandås (2009) who find that the possible existence of hidden depth at the best opposite quote significantly increases the use of market orders.

3 Why the trader chooses to buy and sell the stock at these specific prices is not relevant to the point of the model and, hence, are fixed exogenously.

4 The assumption that the order arrival rate is independent of price is justified in the model because assuming a price dependent order arrival rate would give no additional insight into the impact of the possible existence of iceberg orders in the LOB on small investors' welfare. Hence, for expositional ease, we assume $\lambda$ is price independent.
} 
If most of the visible orders in the book are owing to full orders that have been placed, then it is likely that there will be little hidden depth in the LOB. However, if most of the visible orders are iceberg peaks, then it is likely that there is quite a lot of hidden depth. Thus $\left|\mathrm{v}_{\tau}^{j}\right|=\left|\mathrm{v}_{\tau}^{j i}\right|+\left|\mathrm{v}_{\tau}^{j f}\right|$, and $\left|\mathrm{v}_{\tau}^{j i}\right|$ and $\left|\mathrm{v}_{\tau}^{j f}\right|$ signal to the investor the absence or presence of hidden depth.

To determine the optimal time at which to place his buy and sell orders, the investor must estimate the likelihood of these being filled at $A$ and $B^{H}$, respectively. This is related to the transparency of the book. At $\tau_{0}$, when he starts to monitor the order flow of the asset as recorded in the LOB, the investor cannot distinguish between those visible orders that have hidden depth and those that do not. Thus, his initial prior over whether the visible net demand is the true net demand of the asset at any recorded price is $p_{0}=50 \%$. This belief is updated in a Bayesian manner every time a new order arrives in the book because the investor decides whether each order he sees entering the book is a full order (with no hidden depth) which we denote as $F$, or the release of an existing iceberg tranche (i.e., has hidden depth associated with it), denoted by $I$. By this we mean that if a new tranche of the iceberg order is released to the visible part of the book, this alters the LOB in a systematic way from what would be expected after a given trade, which signals the presence of hidden depth. Of course, the change could be due to the placement of a usual full limit order, but if the investor starts to see a pattern of say, $x$ orders entering the book in a systematic way every so often when a trade is executed, he deems these orders as being a likely iceberg tranche release.

The conditional probability that the true state of the LOB at price $j$ is accurately represented by what is visible (i.e., that all visible orders come from full orders placed and have no hidden depth) is given by:

$$
\begin{aligned}
P\left(F|| \mathrm{v}_{\tau}^{j f}|,| \mathrm{v}_{\tau}^{j i} \mid\right) & =\frac{P\left(\left|\mathrm{v}_{\tau}^{j f}\right|,\left|\mathrm{v}_{\tau}^{j i}\right| \mid F\right) P(F)}{P\left(\left|\mathrm{v}_{\tau}^{j f}\right|,\left|\mathrm{v}_{\tau}^{j i}\right| \mid F\right) P(F)+P\left(\left|\mathrm{v}_{\tau}^{j f}\right|,\left|\mathrm{v}_{\tau}^{j i}\right| \mid I\right) P(I)} \\
& =\frac{\left(\begin{array}{c}
\left|\mathrm{v}_{\tau}^{j}\right| \\
\left|\mathrm{v}_{\tau}^{j f}\right|
\end{array}\right) \theta^{\left|\mathrm{v}_{\tau}^{j f}\right|}(1-\theta)^{\left|\mathrm{v}_{\tau}^{j i}\right|} p_{0}}{\left(\begin{array}{c}
\left|\mathrm{v}_{\tau}^{j}\right| \\
\left|\mathrm{v}_{\tau}^{j f}\right|
\end{array}\right) \theta^{\left|\mathrm{v}_{\tau}^{j f}\right|}(1-\theta)^{\left|\mathrm{v}_{\tau}^{j i}\right|} p_{0}+\left(\begin{array}{c}
\left|\mathrm{v}_{\tau}^{j}\right| \\
\left|\mathrm{v}_{\tau}^{j i}\right|
\end{array}\right) \theta^{\left|\mathrm{v}_{\tau}^{j i}\right|}(1-\theta)^{\left|\mathrm{v}_{\tau}^{j f}\right|}\left(1-p_{0}\right)} \\
& =\frac{\theta^{k_{\tau}^{j}}}{\theta^{k_{\tau}^{j}}+(1-\theta)^{k_{\tau}^{j}}} \\
& :=p\left(k_{\tau}^{j}\right),
\end{aligned}
$$

where $p_{0}=0.5$ (as discussed), and $k_{\tau}^{j}:=\left|\mathrm{v}_{\tau}^{j f}\right|-\left|\mathrm{v}_{\tau}^{j i}\right|$ denotes the difference between the visible net demand generated by orders he believes to be full orders with no hidden depth, and the visible net demand generated by the tranches of iceberg orders that have been released and, thus, have hidden depth associated with them.

We interpret $p\left(k_{\tau}^{j}\right)$, denoted by $p_{\tau}^{j}$ hereafter, in the following way. The larger is $\left|\mathrm{v}_{\tau}^{j i}\right|$, the more offers in the visible part of the book that are believed to come from iceberg orders relative to full orders. Hence, the more likely it is that there is hidden 
depth at price $j$ and the lower is $p_{\tau}^{j}$. If $Q>\left|\mathrm{v}_{\tau}^{j}\right|$, then he has more orders he wishes to buy or sell at $j$ than he sees available at time $\tau$. Hence, he is uncertain whether his order will be executed fully if he submits at $\tau$, but if the likelihood that there is hidden depth present is high, then translates to a greater likelihood of having his order filled. Hence, the lower is $p_{\tau}^{j}$, the more likely he deems it that his order will be filled. In other words, $p_{\tau}^{j}$ represents the probability that his order will not get filled at $j$ if submitted at time $\tau$. If $Q \leq\left|\mathrm{v}_{\tau}^{j}\right|$, then he knows for sure that his order will be filled.

The inverse function of Eq. (1) is given by

$$
k_{\tau}^{j}:=k\left(p_{\tau}^{j}\right)=\frac{\ln \left(\frac{1-p_{\tau}^{j}}{p_{\tau}^{j}}\right)}{\ln \left(\frac{1-\theta}{\theta}\right)}
$$

which is monotonically increasing in $p_{\tau}^{j}$.

\subsection{Set-up of the optimal stopping problems}

The investor's objective is to maximise his expected discounted payoff from the roundtrip trade. He must solve two optimal stopping problems: (i) he must determine the optimal time at which to submit his market order to buy $Q$ units of the stock at $A$, and (ii) he must determine the optimal time at which to submit his market order to sell the $Q$ units of at $B^{H}$. Figure 1 depicts the two phases of the investor's problem with expected payoffs which are introduced below.

\subsubsection{The buy problem}

Suppose at some time $\tau \geq \tau_{0}$ the investor is waiting to buy $Q$ units of the stock at $A$. If $\mathrm{v}_{\tau}^{A}>0$, then he knows that there is an excess of buy orders in the book at $A$ waiting to be filled so he does not submit because he knows for sure that his order will not be filled. If $\mathrm{v}_{\tau}^{A}<0$ and, moreover, if $Q \leq\left|\mathrm{v}_{\tau}^{A}\right|$ then he knows with certainty that his order will be fully executed since there are enough visible sell orders available. However, if $\mathrm{v}_{\tau}^{A} \leq 0$ and $Q>\left|\mathrm{v}_{\tau}^{A}\right|$, he can only assign some positive probability $\left(1-p_{\tau}^{A}\right)$ to his

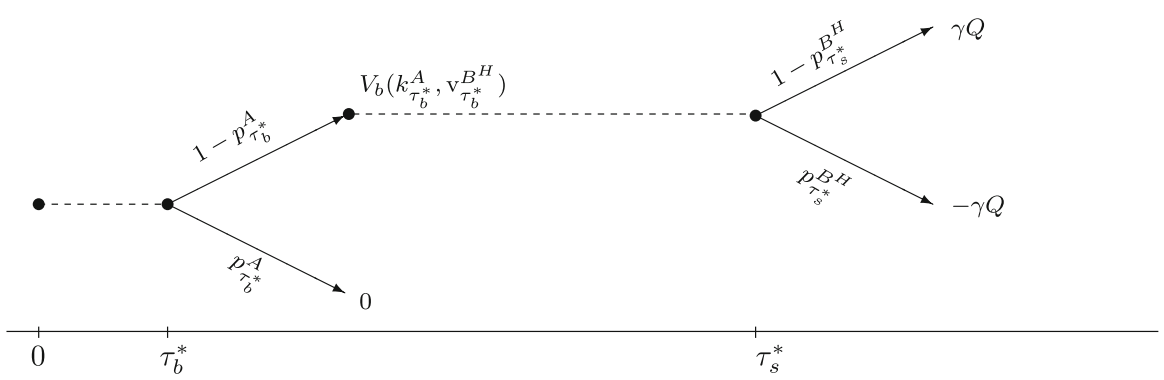

Fig. 1 The timeline and expected payoffs of the round-trip trade 
order being filled at $A$. It will be fully executed if there is sufficient hidden depth on the offer side; that is, if $\left|\mathrm{v}_{\tau}^{A}\right|<Q \leq\left|\mathrm{v}_{\tau}^{A}+\mathrm{h}_{\tau}^{A}\right|$. We assume that if the order is not fully executed at $A$, it is not executed at all; that is, the buy order he submits is a fill-or-kill type of market order. ${ }^{5}$ Hence, his payoff from non-execution is zero.

Buying the stock only has value to the investor if he can sell it in the future at a profit. Hence, it will only be optimal for him to invest if he is sufficiently convinced that he will be able to sell it in the future at $B^{H}$. It is for this reason that he monitors the visible order imbalance at $B^{H}$ while he is waiting to invest because it provides him with an insight into how demand for the stock is evolving at $B^{H}$.

If $\mathrm{v}_{\tau}^{B^{H}}$ increases, this implies buy orders have been submitted to the book at $B^{H}$ and serves as a signal of an increase in demand and greater likelihood of being able to sell at $B^{H}$ in future. However, a decrease in $\mathrm{v}_{\tau}^{B^{H}}$ has the opposite effect. Therefore, if the investor is certain that his buy order will be fully executed at $A$ if he submits at time $\tau$, he will only submit if he is convinced enough that the evolution of demand for the stock at $B^{H}$ is such that he is likely to be able sell it all in the future. To this end, in order to solve for the optimal time to buy the stock, we must also determine the investor's conditional probability $q\left(\mathrm{v}_{\tau}^{B^{H}}\right)$ that he will sell the $Q$ units at $B^{H}$ in the future. We focus on this issue in more detail, and derive explicitly $q\left(\mathrm{v}_{\tau}^{B^{H}}\right)$, in Sect. 3 in which we present and discuss the solution to the buy side problem.

Finally, the optimal time to buy cannot be determined without considering $\mathrm{v}_{\tau}^{B^{H}}$ and $k_{\tau}^{B^{H}}$ in relation to each other. We elaborate on this in Appendix $\mathrm{C}$ where we derive the solution for the optimal time to buy.

The optimal stopping problem for the investor when he is wanting to buy is to find a buying time, $\tau_{b}^{*}>0$, such that

$$
V_{b}^{*}\left(k_{\tau_{b}^{*}}^{A}, \mathrm{v}_{\tau_{b}^{*}}^{B^{H}}\right)=\max _{\tau \geq \tau_{0}} E^{0}\left[e^{-r \tau} V_{b}\left(k_{\tau}^{A}, \mathrm{v}_{\tau}^{B^{H}}\right)\right],
$$

where $r>0$ is the discount rate, $V_{b}\left(k_{\tau}^{A}, \mathrm{v}_{\tau}^{B^{H}}\right)$ denotes the value of submitting a market buy order in states $k_{\tau}^{A}$ and $\mathrm{v}_{\tau}^{B^{H}}$, and $E^{0}$ is the expectation operation at $\tau_{0}=0$. Note that we re-introduce, and provide more detail about, $V_{b}\left(k_{\tau}^{A}, \mathrm{v}_{\tau}^{B^{H}}\right)$ in Sect. 3 in which we derive the buy threshold.

\subsubsection{The sell problem}

Once the investor's buy order is filled, he continues to monitor the order flow dynamics to determine the best time to sell the stock so that his profit from the trade is maximised. By this we mean that he aims to submit his sell market order when the likelihood of there being sufficient depth to fill it at his optimal price $B^{H}$ is high. Since the investor now has an inventory of stock he wishes to sell, we assume that his sell order is a usual market order and not of fill-or-kill type. At some time $\tau_{s}>\tau_{b}$, where $\tau_{b}$ denotes the

\footnotetext{
5 This is a reasonable assumption since investors without inventory positions often rely extensively on socalled fill-or-kill market orders. Additionally, assuming the buy order is a usual market order complicates the model without providing any additional insight.
} 
time at which he purchased the stock, he submits an order to sell the $Q$ units of the asset at $B^{H}$, where $B^{H}:=A e^{r\left(\tau_{s}-\tau_{b}\right)}+\gamma$, for some $\gamma \geq 0$. Hence, at time $\tau_{s}$ he will make a profit of $Q \gamma$ from the trade if executed fully. The order will be executed fully at $B^{H}$ if and only if buy orders prevail at $B^{H}$ so that $Q \leq \mathrm{v}_{\tau_{s}}^{B^{H}}+\mathrm{h}_{\tau_{s}}^{B^{H}}$ for $\mathrm{v}_{\tau_{s}}^{B^{H}}+\mathrm{h}_{\tau_{s}}^{B^{H}}>0$. If $Q>\mathrm{v}_{\tau_{s}}^{B^{H}}+\mathrm{h}_{\tau_{s}}^{B^{H}}$, the order must walk down the book in search of execution since it is of usual type. If this is the case, then the $Q$ units are sold through a series of trades at a range of prices $\left\{B_{m}\right\}_{m=1}^{M} \leq B^{H}$. We assume that the average execution price, denoted by $B^{L}<B^{H}$ such that $B^{L}=\sum_{m=1}^{M} q_{m} B_{m} / Q$, with $\sum_{m=1}^{M} q_{m}=Q$, results in a loss for the investor. In particular, we define $B^{L}:=A e^{r\left(\tau_{s}-\tau_{b}\right)}-\gamma$, so that his loss at $\tau_{s}$ would be $\gamma Q$.

The optimal stopping problem for the investor when he is wanting to sell is to find a selling time, $\tau_{s}^{*}>\tau_{b}^{*}$, such that

$$
V_{s}^{*}\left(k_{\tau_{s}^{*}}^{B^{H}}\right)=\max _{\tau>\tau_{b}} E^{0}\left[e^{-r \tau} V_{s}\left(k_{\tau}^{B^{H}}\right)\right],
$$

where $V_{s}\left(k_{\tau}^{B^{H}}\right)$ denotes the expected payoff from selling in state $k_{\tau}^{B^{H}}$. This is given by

$$
\begin{aligned}
V_{s}\left(k_{\tau}^{B^{H}}\right) & =p_{\tau}^{B^{H}}\left(B^{L}-A e^{r\left(\tau-\tau_{b}\right)}\right) Q+\left(1-p_{\tau}^{B^{H}}\right)\left(B^{H}-A e^{r\left(\tau-\tau_{b}\right)}\right) Q \\
& =\left(1-2 p_{\tau}^{B^{H}}\right) Q \gamma .
\end{aligned}
$$

In summary, the tradeoffs in the model from submitting orders and waiting are as follows. While submitting an order to purchase the stock does not penalise the investor if it is not executed, submission is still costly. This is because if it is executed fully, he loses an amount of capital $Q A$ which he will only recoup in full if there is sufficient demand for the stock in the future that he can sell it all off at a higher price $B^{H}$. The future evolution of demand is uncertain and, hence, before submission he must be sufficiently convinced about being able to sell in future. Uncertainty is resolved by examining the visible net demand flow in the LOB at $B^{H}$. Once he has executed his order to buy, if he submits his order to sell when there is sufficient depth on the bid side of the LOB at the higher price, then he will make a profit of $\gamma Q$ from the trade, but if there is not sufficient depth, he will make a loss of this amount instead. Hence, he must be careful about only submitting his order to sell when the depth is sufficiently high. He examines $\mathrm{v}_{\tau}^{B^{H}}$ for all $\tau<\tau_{s}$ to determine this time.

\section{The solution of the model}

In this section we solve the optimal stopping problems (3) and (4). We begin by solving the sell threshold since selling is a stand-alone decision for the investor. However, the value of buying the stock is dependent on the value of selling it and, thus, must be solved via backward induction. We also present the fully transparent case such that 
the trader submits his orders to fully transparent markets where there is no possibility of hidden depth.

\subsection{Sell threshold}

To determine the optimal time at which to submit a market order to sell the $Q$ units of the stock at $B^{H}$, the investor determines a threshold in $k_{\tau}^{B^{H}}$, denoted by $k_{\tau_{s}^{*}}^{B^{H}}$, such that he will sell for all $k_{\tau}^{B^{H}} \leq k_{\tau_{s}^{*}}^{B^{H}}$ and not otherwise. The reasoning is as follows.

When the investor buys the stock at $A$ at time $\tau_{b}, \mathrm{v}_{\tau_{b}}^{B^{H}}<0$. This is because $B^{H}>A$ by assumption and, thus, it is reasonable to presume there will not be any buy limit orders for the stock at $B^{H}$ waiting in the LOB at time $\tau_{b}$ for incoming sell orders to execute against them because the stock can be bought for a lower price $A$. Hence, sell orders prevail at $B^{H}$ and the probability of the investor not having his sell market order filled at $B^{H}$ at time $\tau_{b}$ is one. He will only sell when he is sufficiently convinced that his full order will be filled at $B^{H}$. He will be certain this will be the case at some time $\tau>\tau_{b}$ if $\mathrm{v}_{\tau}^{B^{H}} \geq Q$. However, since there can be hidden depth through buy iceberg orders being placed at $B^{H}$, the investor does not need to wait until $\mathrm{v}_{\tau}^{B^{H}} \geq Q$ since it will get fully executed at $B^{H}$ if $0<\mathrm{v}_{\tau}^{B^{H}}<Q \leq \mathrm{v}_{\tau}^{B^{H}}+\mathrm{h}_{\tau}^{B^{H}}$. Thus, he will submit his order to sell when he is sufficiently convinced that $Q \leq \mathrm{v}_{\tau}^{B^{H}}+\mathrm{h}_{\tau}^{B^{H}}$. When this is the case, the probability that his sell order will not be executed at $B^{H}$ is lower than $p_{\tau_{b}}^{B^{H}}$ (i.e. certainty) and, since $k_{\tau}^{B^{H}}$ is monotonic and increasing in $p_{\tau}^{B^{H}}, k_{\tau}^{B^{H}}<k_{\tau_{b}}^{B^{H}}$. Hence, the process hits the sell threshold from above implying that the lower is $k_{\tau_{s}^{*}}^{B^{H}}$, the longer the investor waits before selling.

The solution to Eq. (4) is stated in the following proposition.

Proposition 1 Suppose the risk-neutral investor is wanting to sell $Q$ units of the asset at some price $B^{H}$ at time $\tau \geq \tau_{b}$,

1. If $v_{\tau}^{B^{H}}<0$, it is never optimal for him to submit a sell market order at $B^{H}$.

2. If $v^{B^{H}} \geq 0$, it is optimal to submit a sell market order when $k_{\tau}^{B^{H}}$ is at or below

$$
k_{\tau_{s}^{*}}^{B^{H}}=\frac{\ln \left(\frac{1-p_{\tau_{s}^{*}}^{B^{H}}}{p_{\tau_{s}^{*}}^{B H}}\right)}{\ln \left(\frac{1-\theta}{\theta}\right)}
$$

such that

$$
p_{\tau_{s}^{*}}^{B^{H}}=\frac{(r+\lambda(1-\theta))\left(r+\lambda\left(1-\beta_{2}\right)\right)-\lambda^{2} \theta(1-\theta)}{(2 r+\lambda)\left(r+\lambda\left(1-\beta_{2}\right)\right)-2 \lambda^{2} \theta(1-\theta)}
$$

and

$$
\beta_{2}=\frac{r+\lambda}{2 \lambda}-\frac{1}{2} \sqrt{\left(\frac{r+\lambda}{\lambda}\right)^{2}-4 \theta(1-\theta)} .
$$

Moreover, $p_{\tau_{s}^{*}}^{B^{H}}$ is a well-defined probability. 
Proof See Appendix B.

\subsection{Buy threshold}

The investor wishes to purchase $Q$ units of the asset at some time $\tau$ at $A$. If $\mathrm{v}_{\tau}^{A}<0$ and if $Q \leq\left|\mathrm{v}_{\tau}^{A}\right|$, then his order will be fully executed with certainty, but entering into the trade only has value for the investor if he is sufficiently convinced that he will be able to sell his $Q$ units in the future for a profit. Hence, there is value for him in waiting before submitting his market buy order. He evaluates his option to buy at each instant from the perspective of a seller because once he buys, he immediately acquires the option to sell. He will only buy the stock if the value from investing exceeds the value from waiting. In this case, the value from waiting is not related to gaining information about whether his order will be fully executed because he knows with certainty it will be, but over his expectation that the demand for the stock will increase sufficiently in the future for him to be able to sell $Q$ units at $B^{H}$. Indeed, even for $\mathrm{v}_{\tau}^{A}<0$ and $Q>\left|\mathrm{v}_{\tau}^{A}\right|$ whereby his buy order will not be filled with certainty, his value of waiting is not related to gaining information about whether his order will be filled at $A$. This is because the order is of fill-or kill type and, thus, if it is not filled, the investor is no worse off than if he had not submitted it at all.

He will submit his order to buy at $A$ when he is sufficiently convinced that the demand for the stock will increase in the future so that he can make a profit on selling it. This implies that we need to find a buying threshold which pertains to $B^{H}$.

Recall that at the time of buying the asset, $\mathrm{v}_{\tau_{b}}^{B^{H}}<0$. This implies that the limit orders sitting in the book at $B^{H}$ at time $\tau_{b}$ are sell orders. In fact we presume that $\mathrm{v}_{\tau}^{B^{H}}<0$ for all $\tau_{0} \leq \tau \leq \tau_{b}$, which is a reasonable presumption. If a sell limit order enters the LOB at $B^{H}$, then $\Delta \mathrm{v}_{\tau}^{B^{H}}<0$. In other words, $\mathrm{v}_{\tau}^{B^{H}}$ becomes more negative and this is a negative signal to the investor in terms of the future demand being sufficiently high for him to be able to sell. On the other hand, if an aggressive buy order ${ }^{6}$ (either market or limit) enters at $B^{H}$, then $\Delta \mathrm{v}_{\tau}^{B^{H}}>0$, and this is a positive signal regarding future demand. Hence, we want to determine a threshold in $\mathrm{v}_{\tau}^{B^{H}}$, denoted by $\mathrm{v}_{\tau_{b}^{*}}^{B^{H}}$, at or above which the investor will submit an order to buy the stock.

We assume that when the investor starts to monitor the order flow at $\tau_{0}$, he has a prior belief $P(S)=q_{0}$ that the demand for the asset is such that he will be able to sell it at $B^{H}$ in the future. Every time he sees a buy or sell order enter the LOB at $B^{H}$, this belief is revised in a Bayesian way. Hence, the visible net order imbalance $\mathrm{v}_{\tau}^{B^{H}}$ is a signal to the investor about future demand at that price. The signal is an accurate representation of the future demand with probability $\eta \in(0.5,1)$. For example, the higher is the visible order book imbalance, the better the outlook in terms of future demand. However, many orders (eg. fleeting orders ${ }^{7}$ ) are placed in LOBs which are not

\footnotetext{
6 An aggressive order is one that crosses the bid-ask spread. An aggressive buy order will be placed at the offer price or higher.

7 Fleeting orders are limit orders which are canceled shortly after they are submitted. They are typically priced more aggressively than limit orders with longer lives (see Hasbrouck and Saar 2009). One of the
} 
reliable representations of demand for the asset, but impact the visible order imbalance nonetheless. Thus, $\eta$ is a measure of the quality of $\mathrm{v}_{\tau}^{B^{H}}$ as a signal of future market demand for the stock at $B^{H}$.

We model the buy and sell orders as binomially distributed random variables with parameter $\eta$. Then the conditional probability at time $\tau \leq \tau_{b}$ that he will sell the $Q$ units at $B^{H}$ at some future time $\tau_{s}>\tau_{b}$ is given by

$$
\begin{aligned}
P\left(S \mid \mathrm{v}_{\tau}^{B^{H}}\right) & =\frac{P\left(\mathrm{v}_{\tau}^{B^{H}} \mid S\right) P(S)}{P\left(\mathrm{v}_{\tau}^{B^{H}} \mid S\right) P(S)+P\left(\mathrm{v}_{\tau}^{B^{H}} \mid N S\right) P(N S)} \\
& =\frac{P\left(\mathrm{v}_{\tau}^{B^{H}} \mid S\right)}{P\left(\mathrm{v}_{\tau}^{B^{H}} \mid S\right)+\zeta P\left(\mathrm{v}_{\tau}^{B^{H}} \mid N S\right)}
\end{aligned}
$$

where $S$ and $N S$ denote "Sell" and "Not Sell", respectively and $\zeta:=P(N S) / P(S)=$ $\left(1-q_{0}\right) / q_{0}$ is the prior odds ratio.

Now

$$
P\left(\mathrm{v}_{\tau}^{B^{H}} \mid S\right)=\left(\begin{array}{c}
\left|b_{\tau}^{B^{H}}+s_{\tau}^{B^{H}}\right| \\
\left|b_{\tau}^{B^{H}}\right|
\end{array}\right) \eta^{\left|b_{\tau}^{B^{H}}\right|}(1-\eta)^{\left|s_{\tau}^{B^{H}}\right|},
$$

where $b_{\tau}^{B^{H}}$ denote buy orders at $B^{H}$ at $\tau$, and $s_{\tau}^{B^{H}}$ denote sell orders. $\eta$ is the success probability and buy orders imply success in this case (i.e., event " $S$ ") because the more buy orders, the more likely the investor will be able to sell in the future. Similarly,

$$
P\left(\mathrm{v}_{\tau}^{B^{H}} \mid N S\right)=\left(\begin{array}{c}
\left|b_{\tau}^{B^{H}}+s_{\tau}^{B^{H}}\right| \\
\left|s_{\tau}^{B^{H}}\right|
\end{array}\right) \eta^{\left|s_{\tau}^{B^{H}}\right|}(1-\eta)^{\left|b_{\tau}^{B^{H}}\right|} .
$$

However, at time $\tau,\left|b_{\tau}^{B^{H}}\right|=0$ and $\left|s_{\tau}^{B^{H}}\right| \equiv-\mathrm{v}_{\tau}^{B^{H}}$ because $\mathrm{v}_{\tau}^{B^{H}}<0$. Substituting in Eq. (9)

$$
\begin{aligned}
P\left(S \mid \mathrm{v}_{\tau}^{B^{H}}\right) & =\frac{\eta_{\tau}^{\mathrm{V}_{\tau}^{B^{H}}}}{\eta_{\tau}^{\mathrm{V}_{\tau}^{B^{H}}}+\zeta(1-\eta)^{\mathrm{V}_{\tau}^{B^{H}}}} \\
& =q\left(\mathrm{v}_{\tau}^{B^{H}}\right) \\
& =q_{\tau}^{B^{H}} .
\end{aligned}
$$

Equation (10) has inverse function

$$
\mathrm{v}_{\tau}^{B^{H}}=\frac{\ln \left(\frac{1-q_{\tau}^{B^{H}}}{q_{\tau}^{B^{H}}}\right)-\ln \zeta}{\ln \left(\frac{1-\eta}{\eta}\right)}
$$

which monotonically increases in $q_{\tau}^{B^{H}}$.

Footnote 7 continued

main reasons investors use such orders is to search for latent liquidity in markets in which there is hidden depth. Hence, they do not necessarily represent an investor's shift in demand for the asset. 
Finally, we revisit Eq. (3) and provide some structure to $V_{b}\left(k_{\tau}^{A}, \mathrm{v}_{\tau}^{B^{H}}\right)$. When the investor buys, since $\mathrm{v}_{\tau_{b}}^{B^{H}}<0$, he will not sell immediately since he knows with certainty that his order will not be filled at $B^{H}$. In fact, even when the next aggressive buy order enters at $B^{H}$, it is not likely his sell threshold will be reached. Hence, when he buys, he acquires the option to sell pertaining to this scenario, denoted as $V_{s 1}\left(k_{\tau_{b}}^{B^{H}}\right)$ (see Scenario 1 and Eq. (A.7) in Appendix B). Moreover, the investor will only fill his order at $A$ at time $\tau_{b}$ with probability $\left(1-p_{\tau_{b}}^{A}\right)$, and with certainty if $Q \leq\left|\mathrm{v}_{\tau_{b}}^{A}\right|$. Therefore,

$$
V_{b}\left(k_{\tau_{b}}^{A}, \mathrm{v}_{\tau_{b}}^{B^{H}}\right)=\left(1-p_{\tau_{b}}^{A}\right) V_{s 1}\left(k_{\tau_{b}}^{B^{H}}\right)
$$

Proposition 2 Suppose a risk-neutral investor is wanting to buy $Q$ units of the asset at some price $A$ at time $\tau \geq \tau_{0}$, in order to sell at some price $B^{H}>A$ at a later date

1. If $v_{\tau}^{A}>0$, it is never optimal for him to submit a market order to buy the asset at $A$.

2. If $v_{\tau}^{A} \leq 0$ and $v_{\tau}^{B^{H}}<0$, it is optimal to submit a market buy order at $A$ when $v_{\tau}^{B^{H}}$ is at or above

$$
v_{\tau_{b}^{*}}^{B^{H}}=\frac{\ln \left(\frac{1-q_{\tau_{b}^{*}}^{B^{H}}}{q_{\tau_{b}^{*}}^{B^{H}}}\right)-\ln \zeta}{\ln \left(\frac{1-\eta}{\eta}\right)},
$$

such that

$$
\begin{aligned}
q_{\tau_{b}^{*}}^{B^{H}} & =\frac{\eta-1}{2 \eta-1}+\frac{\beta_{2}}{2 \eta-1}\left(\frac{r+\lambda}{\lambda}-\frac{\alpha_{1} \lambda \eta(1-\eta)}{\alpha_{1}(r+\lambda)-\lambda \eta(1-\eta)}\right) \\
& \left(\frac{\theta}{(1-\theta) \beta_{2}^{2}+\theta^{3}}\right)
\end{aligned}
$$

and $0<q_{\tau_{b}^{*}}^{B^{H}}<1$

Proof See Appendix C

\subsection{The fully transparent case}

We present the fully transparent case such that the trader submits orders to fully transparent markets. This enables us to determine whether small traders are better off submitting their orders to markets permitting the placement of iceberg orders.

\subsubsection{Fully transparent sell threshold}

Since there is no hidden depth presence in this case, $\left|\mathrm{v}_{\tau}^{B^{H}}{ }^{H}\right|=0$. Hence, $k_{\tau}^{B^{H}}=$ $\mathbf{v}_{\tau}^{B^{H} f} \equiv \mathbf{v}_{\tau}^{B^{H}}$. Therefore, the optimal policy for the trader is to sell whenever $v_{\tau}^{B^{H}} \geq Q$, and not otherwise. 
Notably, $\mathrm{v}_{\tau}^{B^{H}}$ in the fully transparent market is equivalent to the visible depth that comes from full orders only in the iceberg market. In the iceberg market, there is also the depth that can arise from iceberg orders (both the visible part and the hidden part). Therefore, the depth in the transparent market is lower than the depth in the iceberg market, which is in line with empirical findings (eg. Anand and Weaver 2004; Aitken et al. 2001).

Proposition 3 In the absence of hidden depth, it is optimal for the trader to submit an order to sell at $B^{H}$ at time $\tau>\tau_{b}$ if and only if $v_{\tau}^{B^{H}} \geq Q$.

\subsubsection{Fully transparent buy threshold}

When the trader is considering submitting an order to buy, as previously discussed, he is not interested in the likely presence of hidden depth at this stage. Therefore, his optimal buy strategy is the same whether there may be hidden depth or not. This leads to the following proposition:

Proposition 4 In the absence of hidden depth, it is optimal for the trader to submit an order to buy at $A$ at time $\tau_{b}$ for all $v_{\tau}^{B^{H}} \geq v_{\tau_{b}^{*}}^{B^{H}}$, where $v_{\tau_{b}^{*}}^{B^{H}}$ is given by Eq. (13), and otherwise to wait.

\section{Welfare analysis}

In this section we compare the trader's welfare in the case of potential hidden depth with the fully transparent case. We assume that he adheres to the optimal buy and sell timing strategies derived above. We derive the welfare function for the iceberg case, and adapt it according to the results in Sect. 3 for the fully transparent case.

The current (time 0 ) expected discounted total surplus with critical levels $v_{\tau_{b}^{*}}^{B^{H}}$ and $k_{\tau_{s}^{*}}^{B^{H}}$ and first passage times $\tau_{b}^{*}$ and $\tau_{s}^{*}$ is given by

$$
\bar{W}\left(\mathrm{v}_{\tau_{b}^{*}}^{B^{H}}, k_{\tau_{s}^{*}}^{B^{H}}\right)=\left(1-p_{\tau_{b}^{*}}^{A}\right) V_{s}^{*}\left(k_{\tau_{s}^{*}}^{B^{H}}\right),
$$

where $V_{s}^{*}\left(k_{\tau_{s}^{*}}^{B^{H}}\right)$ (given by Eq. 4) is the current expected discounted value from selling at $\tau_{s}^{*}$. However, he will only get this payoff if his buy order is filled at $A$ at $\tau_{b}^{*}$; i.e., with probability $1-p_{\tau_{b}^{*}}^{A}$.

The uncertainty over the first passage times through $\tau_{b}^{*}$ and $\tau_{s}^{*}$ is incorporated in a similar vein to that in Thijssen et al. (2006). Define the ex ante expected total welfare from the round trip trade at time $\tau_{0}=0, W\left(\mathrm{v}_{\tau_{b}^{*}}^{B^{H}}, k_{\tau_{s}^{*}}^{B^{H}}\right)$, to be the expectation of the discounted total surplus over the first passage times through $v_{\tau_{b}^{*}}^{B^{H}}$ and $k_{\tau_{s}^{*}}^{B^{H}}$. Thus 


$$
\begin{aligned}
W\left(\mathrm{v}_{\tau_{b}^{*}}^{B^{H}}, k_{\tau_{s}^{*}}^{B^{H}}\right) & :=E_{\mathrm{v}_{\tau_{b}^{*}}^{B^{H}}, k_{\tau_{s}^{*}}^{B^{H}}}^{0}\left[\bar{W}\left(\mathrm{v}_{\tau_{b}^{*}}^{B^{H}}, k_{\tau_{s}^{*}}^{B^{H}}\right)\right] \\
& =E_{\mathrm{v}_{\tau_{b}^{*}}^{B^{H}}}^{0}\left[\left(1-p_{\tau_{b}^{*}}^{A}\right) E_{k_{\tau_{s}^{*}}^{B^{H}}}^{0}\left[V_{s}^{*}\left(k_{\tau_{s}^{*}}^{B^{H}}\right)\right]\right] \\
& =\int_{0}^{T_{b}}\left(1-p_{\tau_{b}^{*}}^{A}\right) E_{k_{\tau_{s}^{*}}^{B^{H}}}^{0}\left[V_{s}^{*}\left(k_{\tau_{s}^{*}}^{B^{H}}\right)\right] f_{\mathrm{v}_{\tau_{b}^{*}}^{B^{H}}}\left(\tau_{b}^{*}\right) d \tau_{b}^{*} \\
& =\int_{0}^{T_{b}}\left(1-p_{\tau_{b}^{*}}^{A}\right)\left(\int_{0}^{T_{s}} V_{s}^{*}\left(k_{\tau_{s}^{*}}^{B^{H}}\right) f_{k_{\tau_{s}^{*}}^{B H}}\left(\tau_{s}^{*}\right) d \tau_{s}^{*}\right) f_{\mathrm{v}_{\tau_{b}^{*}}^{B^{H}}}\left(\tau_{b}^{*}\right) d \tau_{b}^{*},
\end{aligned}
$$

where $\int_{0}^{T_{b}} f_{\mathrm{v}_{\tau_{b}^{*}}^{B^{H}}}\left(\tau_{b}^{*}\right) d \tau_{b}^{*}=P\left(\mathrm{v}_{\tau} \geq \mathrm{v}_{\tau_{b}^{*}}^{B^{H}}\right)$ and $\int_{0}^{T_{s}} f_{k_{\tau_{s}^{*}}^{B^{H}}}\left(\tau_{s}^{*}\right) d \tau_{s}^{*}=P\left(k_{\tau} \leq k_{\tau_{s}^{*}}^{B^{H}}\right)$; i.e; the respective probabilities that the buy and sell thresholds are hit before some times $T_{b}$ and $T_{s}$.

Proposition 5 1. The probability density function of the first passage time through $k_{\tau_{s}^{*}}^{B^{H}}$ is given by:

$$
\begin{aligned}
f_{k_{\tau_{s}^{*}}^{B^{H}}}\left(\tau_{s}^{*}\right)= & \left(\frac{q_{1}\left(k_{\tau_{s}^{*}}^{B^{H}}-1\right)}{q_{2}\left(k_{\tau_{s}^{*}}^{B^{H}}+1\right)}\right)^{k_{\tau_{s}^{*}}^{B^{H}} / 2} \\
& \times \frac{\left|k_{\tau_{s}^{*}}^{B^{H}}\right|}{\tau_{s}^{*}} I_{\left|k_{\tau_{s}^{*}}^{B^{H}}\right|}\left(2 \lambda \sqrt{q_{1}\left(k_{\tau_{s}^{*}}^{B^{H}}-1\right) q_{2}\left(k_{\tau_{s}^{*}}^{B^{H}}+1\right)} \tau_{s}^{*}\right) e^{-\lambda \tau_{s}^{*}},
\end{aligned}
$$

for all $k_{\tau_{s}^{*}}^{B^{H}}$, where

$$
I_{k_{\tau_{s}^{*}}^{B H}}(x)=\sum_{n=0}^{\infty} \frac{1}{n ! \Gamma\left(n+k_{\tau_{s}^{*}}^{B^{H}}+1\right)}\left(\frac{x}{2}\right)^{2 n+k_{\tau_{s}^{*}}^{B^{H}}}
$$

is the modified Bessel function with parameter $k_{\tau_{s}^{*}}^{B^{H}} \cdot \Gamma(\cdot)$ denotes the Gamma function and

$$
q_{1}\left(k_{\tau_{s}^{*}}^{B^{H}}-1\right)=\frac{\theta^{k_{\tau_{s}^{*}}^{B^{H}}}+(1-\theta)^{k_{\tau_{s}^{*}}^{B^{H}}}}{\theta^{k_{\tau_{s}^{*}}^{B^{H}}-1}+(1-\theta)^{k_{\tau_{s}^{*}}^{B^{H}}-1}}
$$

and

$$
q_{2}\left(k_{\tau_{s}^{*}}^{B^{H}}+1\right)=\theta(1-\theta) \frac{\theta^{k_{\tau_{s}^{*}}^{B^{H}}-2}+(1-\theta)^{k_{\tau_{s}^{*}}^{B^{H}}-2}}{\theta^{k_{\tau_{s}^{*}}^{B^{H}}-1}+(1-\theta)^{k_{\tau_{s}^{*}}^{B^{H}}-1}} .
$$


2. The probability density function of the first passage time through $v_{\tau_{b}^{*}}^{B^{H}}$ is given by:

$$
\begin{aligned}
f_{v_{\tau_{b}^{*}}^{B H}}\left(\tau_{b}^{*}\right)= & \left(\frac{\hat{q}_{1}\left(v_{\tau_{b}^{*}}^{B^{H}}-1\right)}{\hat{q}_{2}\left(v_{\tau_{b}^{*}}^{B^{H}}+1\right)}\right)^{v_{\tau_{b}^{*}}^{B^{H}} / 2} \\
& \times \frac{\left|v_{\tau_{b}^{*}}^{B H}\right|}{\tau_{b}^{*}} I_{\left|v_{\tau_{b}^{*}}^{B H}\right|}\left(2 \lambda \sqrt{\hat{q}_{1}\left(v_{\tau_{b}^{*}}^{B^{H}}-1\right) \hat{q}_{2}\left(v_{\tau_{b}^{*}}^{B^{H}}+1\right)} \tau_{b}^{*}\right) e^{-\lambda \tau_{b}^{*},}
\end{aligned}
$$

for all $v_{\tau_{b}^{*}}^{B^{H}}$, where

$$
\hat{q}_{1}\left(v_{\tau_{b}^{*}}^{B^{H}}-1\right)=\eta(1-\eta) \frac{\eta^{v_{\tau_{b}^{*}}^{B^{H}}-2}+\zeta(1-\eta)^{v_{\tau_{b}^{*}}^{B^{H}}-2}}{\eta^{v_{\tau_{b}^{*}}^{B^{H}}-1}+\zeta(1-\eta)^{v_{\tau_{b}^{*}}^{B^{H}}-1}}
$$

and

$$
\hat{q}_{2}\left(v_{\tau_{b}^{*}}^{B^{H}}+1\right)=\frac{\eta^{v_{\tau_{b}^{*}}^{B}}+\zeta(1-\eta)^{v_{\tau_{b}^{*}}^{B}}}{\eta^{v_{\tau_{b}^{*}}^{B^{H}}-1}+\zeta(1-\eta)^{v_{\tau_{b}^{*}}^{B}-1}} .
$$

Proof See Appendix D.

\subsection{Welfare results}

We plot the ex ante expected total welfare from the round trip trade as a function of the arrival rate of orders to the LOB in the case where hidden depth may be present and the fully transparent case in Fig. 2. Our rationale for choosing $\lambda$ as the variable parameter is that it is neutral in terms hidden depth presence or absence in a way that, say, the quality of orders as signals of depth would not be. However, choosing any of the parameters gives the same qualitative conclusion about the impact of iceberg orders on traders' welfare. The results we obtain are robust to a wide choice of parameter values, but the parameters we choose here are as follows (Table 1):

We observe that welfare is always higher in the fully transparent case (i.e., no hidden depth). Even though the probability of getting his sell order filled in the fully transparent case is lower because depth is lower in the book (see Fig. 3) and he has to wait until he is certain that it will be filled, there is no possibility of making a loss in that case. In the hidden depth case, depth is greater which implies he submits his sell order when he is not certain it will be executed at the high price. Thus, he risks getting his order filled at $B^{L}$ and thereby making a loss, whereas in the fully transparent case he does not face such a risk. Moreover, on the buy side, he does not face any uncertainty over whether it will be filled in the fully transparent case, making his overall expected payoff from the round trip trade higher than in the hidden depth case. 


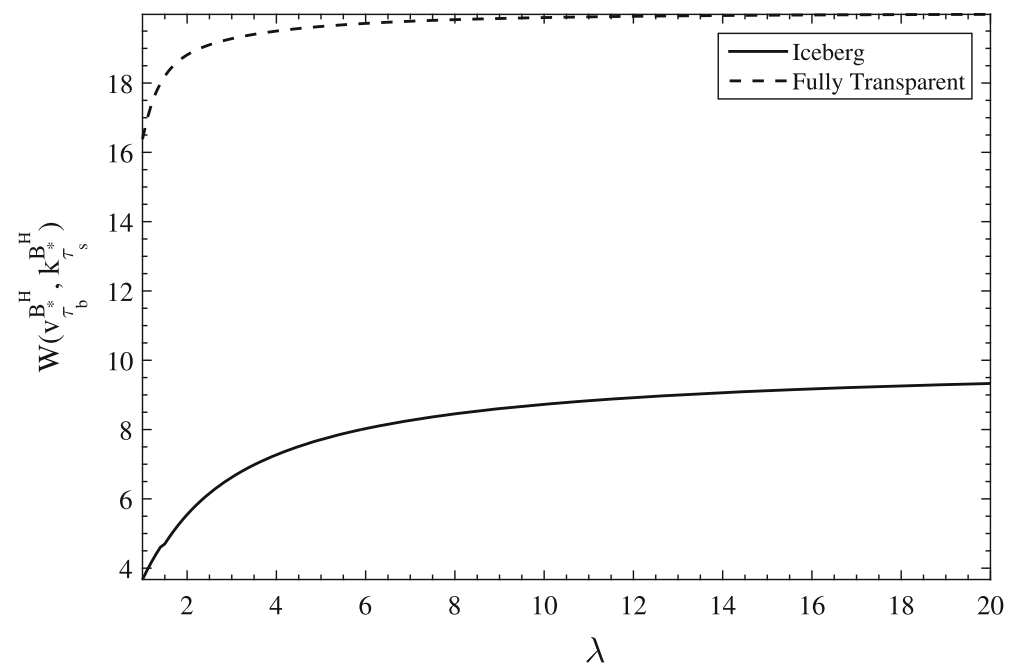

Fig. 2 Expected welfare as a function of $\lambda$ in the iceberg case where hidden depth may be present and the fully transparent case of no hidden depth

Table 1 Parameter values

\begin{tabular}{lll}
\hline$\theta=0.65$ & $\eta=0.75$ & $q_{0}=0.4$ \\
$r=0.1$ & $\lambda=5$ & $Q=2$ \\
$A=4$ & $\gamma=4$ & \\
\hline
\end{tabular}

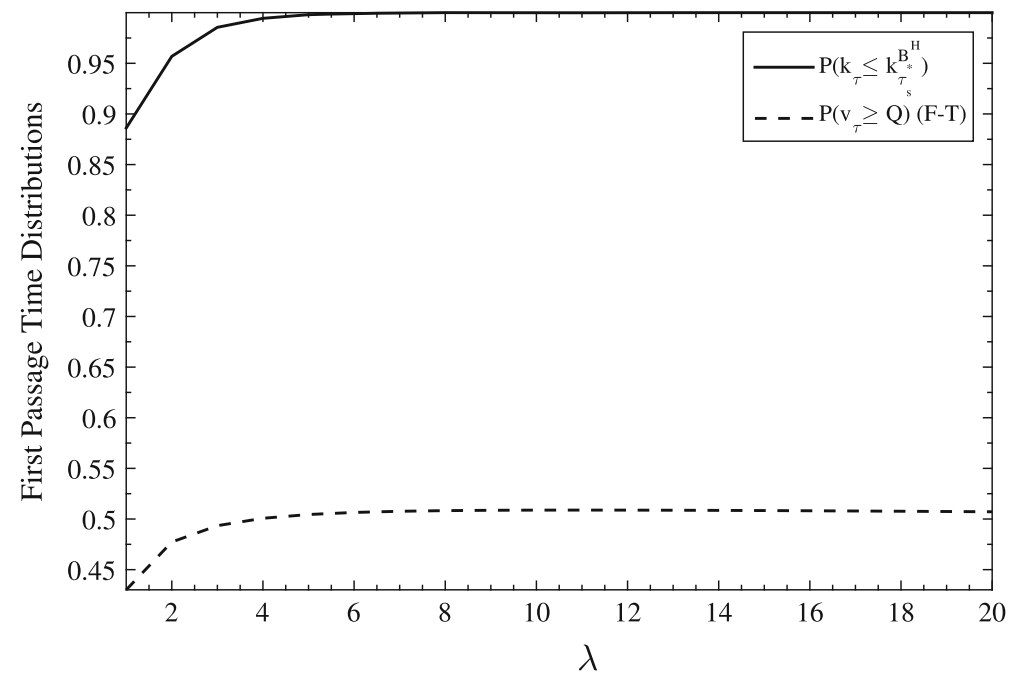

Fig. 3 Probability that the trader's sell order will be filled in the fully transparent $(\mathrm{F}-\mathrm{T})$ case and in the iceberg case as a function of $\lambda$

Hence, we can conclude that even though depth is lower in LOBs which are fully transparent, traders with no use for submitting iceberg orders are still better off submitting orders to fully transparent markets rather than to markets with greater depth being present via the placement of iceberg orders. 


\section{Conclusion}

The use of iceberg orders, which are a special type of limit order which allows traders to hide a portion of their order size in order to manage exposure risk, has become prevalent in many electronic limit order markets. As a consequence, regulators are particularly concerned about the effects of opacity in LOBs on the distribution of welfare between small and large traders. There is ample evidence that large traders who submit iceberg orders benefit in terms of being able to reduce the exposure risk, but there appears to be no investigation into how small traders, who have no use for submitting such orders, are affected. The regulators' concern rests on the fact that liquidity will migrate from transparent markets to markets which allow iceberg order placement and thereby impact on the welfare of those traders, typically small traders, who use transparent markets.

In this paper we develop a model which allows us to investigate whether small traders are better off submitting orders to fully transparent markets or to markets which allow the placement of iceberg orders. We find that, while the former markets are less liquid than markets with iceberg orders, surprisingly, traders are much better off submitting their orders to these markets rather than to the more liquid, but partially opaque markets with iceberg orders.

There have been no empirical investigations, as far as we are aware, which support or refute our result. Nevertheless, our model is a sound representation of the issues traders face when submitting to iceberg markets over fully transparent markets, and hence, we believe our result is robust. In particular, the overarching and most stylised feature of our model is the way in which traders infer the presence of hidden depth in iceberg markets by observing patterns in the limit order book and updating their inferences accordingly. Indeed, according to empirical evidence by DeWinne and D'Hondt (2007) and Frey and Sandås (2009), this is indeed what they do to determine whether their orders are likely to get executed or not. Therefore, our model is adequately underpinned by empirical evidence to give our result sufficient credence. Nonetheless, it would certainly be worthwhile to investigate whether our result is supported by the data which as a topic for future research.

Acknowledgements We thank Jacco Thijssen and Saqib Jafarey for their much appreciated comments and suggestions.

Open Access This article is distributed under the terms of the Creative Commons Attribution 4.0 International License (http://creativecommons.org/licenses/by/4.0/), which permits unrestricted use, distribution, and reproduction in any medium, provided you give appropriate credit to the original author(s) and the source, provide a link to the Creative Commons license, and indicate if changes were made.

\section{Appendix}

\section{A Proof of Proposition 1}

For the investor wanting to sell the asset, his optimal timing strategy is derived as follows. 
1. If $\mathbf{v}_{\tau}^{B^{H}}<0$, then sell orders prevail at $B^{H}$ and if the investor were to submit a market order to sell at $B^{H}$ at $\tau$, he knows with certainty that his order would not be executed at $B^{H}$ but would walk through the book and execute at an average price of $B^{L}<A e^{r\left(\tau-\tau_{b}\right)}$, resulting in a loss.

2. Assume that $\mathrm{v}_{\tau}^{B^{H}} \geq 0$ and that the investor purchased $Q$ units of the asset at time $\tau_{b} \leq \tau$ (where $\tau$ is the current time). We must find a $k_{\tau_{s}^{*}}^{B^{H}}$ at or below which he will submit a market order to sell the asset. In order to determine this threshold level, we must consider what the optimal strategy is if $k_{\tau}^{B^{H}}$ changes by one unit. If, for example, at some time $\tau$ the level of $k_{\tau}^{B^{H}}$ is such that it is optimal for the trader to wait; i.e., $k_{\tau}^{B^{H}}>k_{\tau_{s}^{*}}^{B^{H}}$. Now say an order is submitted and $k_{\tau}^{B^{H}}$ decreases by 20 units such that $k_{\tau}^{B^{H}}-20<k_{\tau_{s}^{*}}^{B^{H}}$; i.e., somewhere in the range $\left[k_{\tau}^{B^{H}}-1, k_{\tau}^{B^{H}}-20\right]$ it changed from it being optimal to wait to being optimal to sell. But there are 20 possible values that the threshold could be in this case. Therefore, in order to solve for the threshold, the approach must be to focus on a narrow range such that there is only one possible value at which that change in optimal strategy could occur. Thus $\Delta k_{\tau}^{B^{H}}= \pm 1$ hereafter.

Scenario 1: Say the state of the process $k_{\tau}^{B^{H}}$ is such that even after the entry of another iceberg release on the bid side (i.e., another signal indicating the presence of hidden depth of buy orders), it will still not be optimal for the investor to submit a sell market order; that is $k_{\tau}^{B^{H}}$ updates to $k_{\tau}^{B^{H}}-1$ which, in turn, strengthens his conviction that his order will be filled since there is further evidence of hidden depth. However, we are supposing that $k_{\tau}^{B^{H}}-1>k_{\tau_{s}^{*}}^{B^{H}}$ implying he is still not sufficiently convinced that it will get executed at $B^{H}$ to submit the sell order. In this case, the associated Bellman equation is given by (cf. Dixit and Pindyck 1994)

$$
\begin{aligned}
V_{s 1}\left(k_{\tau}^{B^{H}}\right) & =e^{-r d t} E^{\tau}\left[V_{s 1}\left(k_{\tau+d t}^{B^{H}}\right)\right] \\
\Longrightarrow r V_{s 1}\left(k_{\tau}^{B^{H}}\right) d t & =(1-r d t) E^{\tau}\left[d V_{s 1}\left(k_{\tau+d t}^{B^{H}}\right)\right],
\end{aligned}
$$

where $V_{s 1}\left(k_{\tau}^{B^{H}}\right)$ denotes the value of the option to sell in state $k_{\tau}^{B^{H}}$ under Scenario 1. Equation (A.1) states that the value of the option to sell in state $k_{\tau}^{B^{H}}$ must equal the expected discounted value an infinitesimal amount of time later.

$$
\begin{aligned}
E^{\tau}\left[d V_{s 1}\left(k_{\tau+d t}^{B^{H}}\right)\right]= & \lambda d t\left[P_{k_{\tau}^{B}{ }^{H}+1}\left(V_{s 1}\left(k_{\tau}^{B^{H}}+1\right)-V_{s 1}\left(k_{\tau}^{B^{H}}\right)\right)\right. \\
& \left.+P_{k_{\tau}^{B}{ }^{H}-1}\left(V_{s 1}\left(k_{\tau}^{B^{H}}-1\right)-V_{s 1}\left(k_{\tau}^{B^{H}}\right)\right)\right],
\end{aligned}
$$

such that $P_{k_{\tau}^{B}{ }^{H}+1}$ denotes the probability of reaching $k_{\tau}^{B^{H}}+1$ from $k_{\tau}^{B^{H}}$, and $P_{k_{\tau}^{B}{ }^{H}-1}$ denotes the probability of reaching $k_{\tau}^{B^{H}}-1$ from $k_{\tau}^{B^{H}}$. Equation (A.1) then becomes 


$$
\frac{r+\lambda}{\lambda} V_{s 1}\left(k_{\tau}^{B^{H}}\right)=P_{k_{\tau}^{B}{ }^{H}+1} V_{s 1}\left(k_{\tau}^{B^{H}}+1\right)+P_{k_{\tau}^{B}{ }^{H}-1} V_{s 1}\left(k_{\tau}^{B^{H}}-1\right) .
$$

Now $P_{k_{\tau}^{B}{ }^{H}+1}$ and $P_{k_{\tau}^{B}{ }^{H}-1}$ are determined as follows. Recall that $k_{\tau}^{B^{H}}:=$ $\mathrm{v}_{\tau}^{B^{H} f}-\mathrm{v}_{\tau}^{B^{H}}{ }^{H}$, where $\mathrm{v}_{\tau}^{B^{H} f}+\mathrm{v}_{\tau}^{B^{H}}{ }^{H}=\mathrm{v}_{\tau}^{B^{H}}$. Since $\mathrm{v}_{\tau}^{B^{H}} \geq 0$, buy orders prevail in the LOB at $B^{H}$. Hence $\mathrm{v}_{\tau}^{B^{H} f}$ are visible buy orders that the investor deems to be full orders, and $\mathrm{v}_{\tau}^{B^{H}}{ }_{i}$ are visible buy orders that are deemed to have hidden depth associated with them. To highlight that these are visible buy orders, we denote $\mathrm{v}_{\tau}^{B^{H} f}$ by $\mathrm{vb}_{\tau}^{B^{H} f}$ and $\mathrm{v}_{\tau}^{B^{H} i}$ by $\mathrm{vb}_{\tau}^{B^{H}}{ }^{H}$ for the moment. Hence

$$
k_{\tau}^{B^{H}} \equiv \mathrm{vb}_{\tau}^{B^{H} f}-\mathrm{vb}_{\tau}^{B^{H} i}
$$

The ways in which $k_{\tau}^{B^{H}}$ can change by one unit are as follows:

- Say a new buy order enters the LOB with probability $P(B)$, and it is deemed by the investor to be a full order. With probability $\theta$ this is correct. Then $k_{\tau}^{B^{H}}$ increases to $\left(\mathrm{vb}_{\tau}^{B^{H} f}+1\right)-\mathrm{vb}_{\tau}^{B^{H}} i=k_{\tau}^{B^{H}}+1$ with probability $P(B) \theta$. However, if that order was actually part of an iceberg order (i.e., investor was incorrect), then $k_{\tau}^{B^{H}}$ decreases to $\mathrm{vb}_{\tau}^{B^{H} f}-\left(\mathrm{vb}_{\tau}^{B^{H}}+1\right)=k_{\tau}^{B^{H}}-1$. The latter occurs w.p. $P(B)(1-\theta)$.

- Say a new buy order enters the LOB with probability $P(B)$, and it is deemed an iceberg order. With probability $\theta$ this is correct. Then $k_{\tau}^{B^{H}}$ decreases to $\mathrm{vb}_{\tau}^{B^{H} f}-\left(\mathrm{vb}_{\tau}^{B^{H}}+1\right)=k_{\tau}^{B^{H}}-1$ with probability $P(B) \theta$. However, if that order was actually a full order (i.e., investor was incorrect), then $k_{\tau}^{B^{H}}$ increases to $\left(\mathrm{vb}_{\tau}^{B^{H} f}+1\right)-\mathrm{vb}_{\tau}^{B^{H}}{ }^{H}=k_{\tau}^{B^{H}}+1$. The latter occurs w.p. $P(B)(1-\theta)$.

- Say a new sell order enters the LOB w.p. $(1-P(B))$ and it executed against one of the buys. That buy is deemed a full order and this is accurate. Therefore $k_{\tau}^{B^{H}}$ decreases to $\left(\mathrm{vb}_{\tau}^{B^{H} f}-1\right)-\mathrm{vb}_{\tau}^{B^{H^{H}}}=k_{\tau}^{B^{H}}-1$ w.p. $(1-P(B)) \theta$. If the order it executes against is actually part of an iceberg order, then $k_{\tau}^{B^{H}}$ increases to $\mathrm{vb}_{\tau}^{B^{H} f}-\left(\mathrm{vb}_{\tau}^{B^{H}}{ }^{H}-1\right)=k_{\tau}^{B^{H}}+1$ w.p. $(1-P(B))(1-\theta)$.

- Say a new sell order enters the LOB w.p. $(1-P(B))$ and it executed against one of the buys. That buy is deemed an iceberg order and this is accurate. Therefore $k_{\tau}^{B^{H}}$ increases to $\mathrm{vb}_{\tau}^{B^{H} f}-\left(\mathrm{vb}_{\tau}^{B^{H}}-1\right)=k_{\tau}^{B^{H}}+1$ w.p. $(1-P(B)) \theta$. If the order it executes against is actually a full order, then $k_{\tau}^{B^{H}}$ decreases to $\left(\mathrm{vb}_{\tau}^{B^{H} f}-1\right)-\mathrm{vb}_{\tau}^{B^{H}}{ }^{H}=k_{\tau}^{B^{H}}-1$ w.p. $(1-P(B))(1-\theta)$.

However, in determining $P_{k_{\tau}^{B} H}$ and $P_{k_{\tau}^{B}}{ }^{H}-1$ fully, we must account for the investor's conditional probability that the LOB is accurately represented by what is visible, i.e., $p_{\tau}^{B^{H}}$ (cf. Eq. 1).

- First, if the new visible order to enter the LOB is a buy limit order and is deemed by the investor to be a full (iceberg) order, then the number of visible full buy orders relative to the number of visible iceberg buys increases (decreases) by one unit; i.e., $k_{\tau}^{B^{H}}$ increases to $k_{\tau}^{B^{H}}+1$ (resp. $k_{\tau}^{B^{H}}$ decreases to $k_{\tau}^{B^{H}}-1$ ). 
Hence, the entry of that order makes the LOB a relatively more (less) accurate representation of the true net demand at $B^{H}$. From the investor's perspective, this occurs w.p. $p_{\tau}^{B^{H}}$ (resp. $\left.\left(1-p_{\tau}^{B^{H}}\right)\right)$.

- However, if the new visible order to enter the LOB is a sell limit order and executes against what is deemed to be a full (iceberg) buy order, then $k_{\tau}^{B^{H}}$ decreases to $k_{\tau}^{B^{H}}-1$ (resp. $k_{\tau}^{B^{H}}$ increases to $k_{\tau}^{B^{H}}+1$ ) and the true net demand in LOB is then less (more) accurately represented by the visible part from the investor's perspective. This occurs w.p. $\left(1-p_{\tau}^{B^{H}}\right)$ (resp. w.p. $\left.p_{\tau}^{B^{H}}\right)$.

Putting all this together, $k_{\tau}^{B^{H}}$ increases to $k_{\tau}^{B^{H}}+1$ w.p. $P_{k_{\tau}^{B}}{ }^{H}+1$, where

$$
\begin{aligned}
P_{k^{B}{ }^{H}+1}= & p_{\tau}^{B^{H}}(\theta P(B)+\theta(1-P(B))) \\
& +\left(1-p_{\tau}^{B^{H}}\right)((1-\theta) P(B)+(1-\theta)(1-P(B))) \\
= & p_{\tau}^{B^{H}} \theta+\left(1-p_{\tau}^{B^{H}}\right)(1-\theta) .
\end{aligned}
$$

Similarly

$$
P_{k_{\tau}^{B}{ }^{H}-1}=\left(1-p_{\tau}^{B^{H}}\right) \theta+p_{\tau}^{B^{H}}(1-\theta) .
$$

Replacing for $p_{\tau}^{B^{H}}$ using Eq. (1) and $P_{k_{\tau}^{B}{ }^{H}+1}$ and $P_{k_{\tau}^{B}{ }^{H}-1}$ in Eq. (A.3) yields the second order homogeneous difference equation

$$
\widetilde{V}_{s 1}\left(k_{\tau}^{B^{H}}+1\right)-\frac{r+\lambda}{\lambda} \widetilde{V}_{s 1}\left(k_{\tau}^{B^{H}}\right)+\theta(1-\theta) \widetilde{V}_{s 1}\left(k_{\tau}^{B^{H}}-1\right)=0,
$$

where $\widetilde{V}_{s 1}\left(k_{\tau}^{B^{H}}\right):=\left(\theta^{k_{\tau}^{B^{H}}}+(1-\theta)^{k_{\tau}^{B^{H}}}\right) V_{s 1}\left(k_{\tau}^{B^{H}}\right)$.

Equation (A.6) admits the following general solution

$$
V_{s 1}\left(k_{\tau}^{B^{H}}\right)=\frac{A_{1} \beta_{1}^{k_{\tau}^{B^{H}}}+A_{2} \beta_{2}^{k^{B^{H}}}}{\theta^{k^{B} B^{H}}+(1-\theta)^{k_{\tau}^{B}}},
$$

where $A_{1}$ and $A_{2}$ are constant and $\beta_{1,2}$ are the real roots of the following quadratic equation

$$
\mathcal{Q}(\beta)=\beta^{2}-\left(\frac{r+\lambda}{\lambda}\right) \beta+\theta(1-\theta)=0 .
$$

Now, the higher is $k_{\tau}^{B^{H}}$, the less likely it is that there is sufficient hidden depth in the book to fill the investor's order fully at $B^{H}$ and, hence, the lower is the value of the selling opportunity to the investor. Hence, we impose the condition that

$$
\frac{\partial V_{s 1}\left(k_{\tau}^{B^{H}}\right)}{\partial k_{\tau}^{B^{H}}}<0 .
$$


Letting $\beta_{1}>0$ denote the larger of the two roots, to ensure this condition is always satisfied, we must let $A_{1}=0$. This is because it holds that $0<\beta_{2}<1-\theta<\theta<\beta_{1}$ (cf. Thijssen et al. 2004) and, so, the numerator in (A.7) dominates and $V_{s 1}\left(k_{\tau}^{B^{H}}\right)$ increases in $k_{\tau}^{B^{H}}$ for all $A_{1} \neq 0$. Hence

$$
V_{s 1}\left(k_{\tau}^{B^{H}}\right)=\frac{A_{2} \beta_{2}^{k_{\tau}^{B^{H}}}}{\theta^{k^{B^{H}}}+(1-\theta)^{k_{\tau}^{B^{H}}}} .
$$

Scenario 2: Alternatively, if $k_{\tau}^{B^{H}}$ is such that after one more net iceberg release on the bid side, then it will be optimal for the investor to submit his sell market order; that is $k_{\tau}^{B^{H}}>k_{\tau_{s}^{*}}^{B^{H}}$, but $k_{\tau}^{B^{H}}-1 \leq k_{\tau_{s}^{*}}^{B^{H}}$ or, in other words, $k_{\tau_{s}^{*}}^{B^{H}}<k_{\tau}^{B^{H}} \leq k_{\tau_{s}^{*}}^{B^{H}}+1$. Letting $V_{s 2}(\cdot)$ denote the value of the option to sell in Scenario 2, the Bellman equation is then given by

$$
\begin{aligned}
\frac{r+\lambda}{\lambda} V_{s 2}\left(k_{\tau}^{B^{H}}\right)= & \left(\theta p_{\tau}^{B^{H}}+(1-\theta)\left(1-p_{\tau}^{B^{H}}\right)\right) V_{s 1}\left(k_{\tau}^{B^{H}}+1\right) \\
& +\left((1-\theta) p_{\tau}^{B^{H}}+\theta\left(1-p_{\tau}^{B^{H}}\right)\right) V_{s 0}\left(k_{\tau}^{B^{H}}-1\right)
\end{aligned}
$$

where $V_{s 0}\left(k_{\tau}^{B^{H}}\right)$ is the current expected value obtained from submitting a market sell order in state $k_{\tau}^{B^{H}}$; that is,

$$
\begin{aligned}
V_{s 0}\left(k_{\tau}^{B^{H}}\right) & =Q\left(p_{\tau}^{B^{H}}\left(B^{L}-A e^{r\left(\tau-\tau_{b}\right)}\right)+\left(1-p_{\tau}^{B^{H}}\right)\left(B^{H}-A e^{r\left(\tau-\tau_{b}\right)}\right)\right) \\
& =\left(1-2 p_{\tau}^{B^{H}}\right) Q \gamma .
\end{aligned}
$$

By replacing for $V_{s 1}\left(k_{\tau}^{B^{H}}+1\right)$ and $V_{s 0}\left(k_{\tau}^{B^{H}}-1\right)$ in Eq. (A.11), $k_{\tau_{s}^{*}}^{B^{H}}$ can then be determined by solving for the following value matching conditions:

$$
V_{s 1}\left(k_{\tau_{s}^{*}}^{B^{H}}+1\right)=V_{s 2}\left(k_{\tau_{s}^{*}}^{B^{H}}+1\right)
$$

and

$$
V_{s 2}\left(k_{\tau_{s}^{*}}^{B^{H}}\right)=V_{s 0}\left(k_{\tau_{s}^{*}}^{B^{H}}\right)
$$

From (A.13), we get that

$$
A_{2} \beta_{2}^{k_{\tau_{s}^{*}}^{B^{H}}+1}=\frac{\lambda \theta(1-\theta)}{\lambda\left(\beta_{2}-1\right)-r}\left(\theta^{k_{\tau_{s}^{*}}^{B^{H}}}-(1-\theta)^{k_{\tau_{s}^{*}}^{B^{H}}}\right) Q \gamma
$$

and replacing for this in Eq. (A.14) yields

$$
p_{\tau_{s}^{*}}^{B^{H}}=\frac{(r+\lambda(1-\theta))\left(r+\lambda\left(1-\beta_{2}\right)\right)-\lambda^{2} \theta(1-\theta)}{(2 r+\lambda)\left(r+\lambda\left(1-\beta_{2}\right)\right)-2 \lambda^{2} \theta(1-\theta)} .
$$


This gives

$$
k_{\tau_{s}^{*}}^{B^{H}}=\frac{\ln \left(\frac{1-p_{\tau_{s}^{*}}^{B^{H}}}{p_{\tau_{s}^{*}}^{B^{H}}}\right)}{\ln \left(\frac{1-\theta}{\theta}\right)} .
$$

For completeness, we show that $p_{\tau_{s}^{*}}^{B^{H}}$ is a well-defined probability.

We can re-write Eq. (A.16) as follows:

$$
p_{\tau_{s}^{*}}^{B^{H}}=\frac{\beta_{1}(r+\lambda(1-\theta))-\lambda \theta(1-\theta)}{\beta_{1}(2 r+\lambda)-2 \lambda \theta(1-\theta)},
$$

since $\lambda \beta_{1} \equiv r+\lambda\left(1-\beta_{2}\right)$.

If $r=0$, the numerator of $p_{\tau_{s}^{*}}^{B^{H}}$, denoted by $n\left(p_{\tau_{s}^{*}}^{B^{H}}\right)$, is zero and $\partial n\left(p_{\tau_{s}^{*}}^{B^{H}}\right) / \partial r>0$ since $\partial \beta_{1} / \partial r>0$. Thus, $n\left(p_{\tau_{s}^{*}}^{B^{H}}\right)>0$. Similarly, the denominator of $p_{\tau_{s}^{*}}^{B^{H}}$ is positive since $\theta>1 / 2$ by assumption. Thus, $p_{\tau_{s}^{*}}^{B^{H}}>0$.

Furthermore $p_{\tau_{s}^{*}}^{B^{H}} \leq 1$ iff $\lambda \theta(1-\theta)-\beta_{1}(r+\lambda \theta) \leq 0$. If $r=0$, this is true and $\partial\left(\lambda \theta(1-\theta)-\beta_{1}(r+\lambda \theta)\right) / \partial r<0$. Thus, the condition holds.

Hence, $p_{\tau_{s}^{*}}^{B^{H}}$ is a well-defined probability.

\section{Appendix B: Proof of Proposition 2}

For the investor wanting to buy the asset, his optimal timing strategy is derived as follows.

1. If $\mathrm{v}_{\tau}^{A}>0$, the total number of bids for the stock exceed the total number of offers at price $A$. There is no hidden depth on the offer side at that price or else it would be matched with the available bids. Hence, the investor will never submit a market order to buy the stock at $A$ because, with certainty, it will not be executed fully.

2. If $\mathrm{v}_{\tau}^{A}<0$ and $\mathrm{v}_{\tau}^{B^{H}}<0$, then the investor will monitor the flow of orders for the stock at $B^{H}$ and invest at $A$ when he is convinced that the demand for the asset will increase sufficiently in the future so that he will execute his full sell order at $B^{H}$.

Scenario 1: If $\mathrm{v}_{\tau}^{B^{H}}$ is such that even if one aggressive buy order enters the LOB at $B^{H}$, it will still not be optimal for the investor to submit a buy order; i.e., $\mathrm{v}_{\tau}^{B^{H}}+1<\mathrm{v}_{\tau_{b}^{*}}^{B^{H}}$, then the value of his option to buy in this scenario, denoted as $V_{b 1}\left(\mathrm{v}_{\tau}^{B^{H}}\right)$, is given by the solution to the following Bellman equation (cf. Appendix B)

$$
\frac{r+\lambda}{\lambda} V_{b 1}\left(\mathrm{v}_{\tau}^{B^{H}}\right)=Q_{\mathrm{v}_{\tau}^{B^{H}}+1} V_{b 1}\left(\mathrm{v}_{\tau}^{B^{H}}+1\right)+Q_{\mathrm{v}_{\tau}^{B^{H}}-1} V_{b 1}\left(\mathrm{v}_{\tau}^{B^{H}}-1\right)
$$

where $Q_{\mathrm{v}_{\tau}^{B}{ }^{H}}$ and $Q_{\mathrm{v}_{\tau}^{B}{ }^{H}-1}$ denote the respective probabilities of reaching $\mathrm{v}_{\tau}^{B^{H}}+$ 1 and $\mathrm{v}_{\tau}^{B^{H}}-1$ from $\mathrm{v}_{\tau}^{B^{H}}$. 
For $\mathrm{v}_{\tau}^{B^{H}}<0, \mathrm{v}_{\tau}^{B^{H}}$ increases to $\mathrm{v}_{\tau}^{B^{H}}+1$ iff an only if a buy order enters the book. Thus $P(B)=1$. Additionally, one of the following must occur:

- An aggressive buy order enters the LOB at $B^{H}$ and executes against one of the sells. The order is deemed to be a true representation of future demand and this is accurate. This event occurs with probability $q_{\tau}^{B^{H}} \eta$.

- An aggressive buy order enters the LOB at $B^{H}$ and executes against one of the sells. The order is deemed to be a false order (eg. fleeting) and this is inaccurate. This event occurs with probability $\left(1-q_{\tau}^{B^{H}}\right)(1-\eta)$.

Thus

$$
Q_{k_{\tau}^{B}{ }^{H}+1}=q_{\tau}^{B^{H}} \eta+\left(1-q_{\tau}^{B^{H}}\right)(1-\eta) .
$$

$\mathbf{v}_{\tau}^{B^{H}}$ decreases to $\mathbf{v}_{\tau}^{B^{H}}-1$ iff an only if a sell order enters the book. Then by a similar reasoning to above

$$
Q_{k_{\tau}^{B}{ }^{H}-1}=\left(1-q_{\tau}^{B^{H}}\right) \eta+q_{\tau}^{B^{H}}(1-\eta)
$$

Substituting for $q_{\tau}^{B^{H}}, Q_{k_{\tau}^{B}{ }^{H}+1}$ and $Q_{k_{\tau}^{B}{ }^{H}-1}$ (B.1) gives

$$
\begin{aligned}
\frac{r+\lambda}{\lambda} V_{b 1}\left(\mathrm{v}_{\tau}^{B^{H}}\right)= & \frac{\eta^{\mathrm{V}_{\tau}^{B}}+1}{\eta \mathrm{v}_{\tau}^{B^{H}}}+\zeta(1-\eta)^{\mathrm{V}_{\tau}^{B}} \\
& \left.+\eta(1-\eta) \frac{\eta^{\mathrm{V}_{\tau}^{B}}-1}{\eta^{\mathrm{V}_{\tau}^{B}}+\zeta(1-\eta)^{\mathrm{V}_{\tau}^{B}}+\zeta(1-\eta)^{\mathrm{V}_{\tau}^{B}}}+\mathrm{v}_{\tau}^{B^{B}}+1\right) \\
& V_{b 1}\left(\mathrm{v}_{\tau}^{B^{H}}-1\right) .
\end{aligned}
$$

Equation (B.4) has general solution

$$
V_{b 1}\left(\mathrm{v}_{\tau}^{B^{H}}\right)=\frac{B_{1} \alpha_{1}^{\mathrm{v}_{\tau}^{B^{H}}}+B_{2} \alpha_{2}^{\mathrm{v}_{\tau}^{B^{H}}}}{\eta^{\mathrm{v}_{\tau}^{B}}+\zeta(1-\eta)^{\mathrm{V}_{\tau}^{B^{H}}}},
$$

where $B_{1}$ and $B_{2}$ are constant and $\alpha_{1}$ and $\alpha_{2}$ are the two real roots of the following equation:

$$
\alpha^{2}-\frac{r+\lambda}{\lambda} \alpha+\eta(1-\eta)=0
$$

One condition that the $V_{b 1}\left(\mathrm{v}_{\tau}^{B^{H}}\right)$ must satisfy is that $\lim _{\mathrm{v}_{\tau}^{B^{H}} \rightarrow-\infty} V_{b 1}\left(\mathrm{v}_{\tau}^{B^{H}}\right)=0$. Letting $\alpha_{1}>0$ denote the larger root, it holds that $0<\alpha_{2}<1-\eta<\eta<\alpha_{1}$. This implies that the condition will hold iff $B_{2}=0$. Hence

$$
V_{b 1}\left(\mathrm{v}_{\tau}^{B^{H}}\right)=\frac{B_{1} \alpha_{1}^{\mathrm{v}_{\tau}^{B^{H}}}}{\eta^{\mathrm{v}_{\tau}^{B^{H}}}+\zeta(1-\eta)^{\mathrm{v}_{\tau}^{B}}} .
$$


Scenario 2: Another state of $\mathrm{v}_{\tau}^{B^{H}}$ could be such that if one aggressive buy order at $B^{H}$ depletes the sell side by one, then it will be optimal for the investor to buy; i.e., $\mathrm{v}_{\tau_{b}^{*}}^{B^{H}}-1 \leq \mathrm{v}_{\tau}^{B^{H}}<\mathrm{v}_{\tau_{b}^{*}}^{B^{H}}$. The value of the option to buy in this region, denoted by $V_{b 2}\left(v_{\tau}^{B^{H}}\right)$ is given by the solution to the following bellman equation

$$
\begin{aligned}
\frac{r+\lambda}{\lambda} V_{b 2}\left(\mathrm{v}_{\tau}^{B^{H}}\right)= & \frac{\eta_{\tau}^{\mathrm{V}^{B^{H}}+1}+\zeta(1-\eta)^{\mathrm{V}_{\tau}^{B^{H}}+1}}{\eta^{\mathrm{v}_{\tau}^{B^{H}}}+\zeta(1-\eta)^{\mathrm{V}_{\tau}^{B^{H}}}} V_{b 0}\left(\mathrm{v}_{\tau}^{B^{H}}+1\right) \\
& +\eta(1-\eta) \frac{\eta^{\mathrm{V}_{\tau}^{B^{H}}-1}+\zeta(1-\eta)^{\mathrm{V}_{\tau}^{B^{H}}-1}}{\eta_{\tau}^{\mathrm{v}_{\tau}^{B}}+\zeta(1-\eta)^{\mathrm{V}_{\tau}^{B}}} V_{b 1}\left(\mathrm{v}_{\tau}^{B^{H}}-1\right)
\end{aligned}
$$

where $V_{b 1}\left(\mathrm{v}_{\tau}^{B^{H}}\right)$ is given by (B.5) and $V_{b 0}\left(\mathrm{v}_{\tau}^{B^{H}}\right)$ is the value to the manager from investing in state $\mathrm{v}_{\tau}^{B^{H}}$; i.e.,

$$
V_{b 0}\left(\mathrm{v}_{\tau}^{B^{H}}\right)=\left(1-p\left(k_{\tau}^{A}\right)\right) V_{s 1}\left(k_{\tau}^{B^{H}}\right) \equiv V_{b}\left(k_{\tau}^{A}, \mathrm{v}_{\tau}^{B^{H}}\right)
$$

(cf. Eq. 12).

The threshold, $\mathrm{v}_{\tau_{b}^{*}}^{B^{H}}$ then satisfies the following two value matching conditions

$$
V_{b 1}\left(\mathrm{v}_{\tau_{b}^{*}}^{B^{H}}-1\right)=V_{b 2}\left(\mathrm{v}_{\tau_{b}^{*}}^{B^{H}}-1\right)
$$

and

$$
V_{b 2}\left(\mathrm{v}_{\tau_{b}^{*}}^{B^{H}}\right)=V_{b 0}\left(\mathrm{v}_{\tau_{b}^{*}}^{B^{H}}\right) .
$$

From (B.9) and (B.10) we get

$$
q_{\tau_{b}^{*}}^{B^{H}}=\frac{1}{2 \eta-1}\left(\frac{r+\lambda}{\lambda}-\frac{\alpha_{1} \lambda \eta(1-\eta)}{\alpha_{1}(r+\lambda)-\lambda \eta(1-\eta)}\right) \frac{V_{b 0}\left(\mathrm{v}_{\tau_{b}^{*}}^{B^{H}}\right)}{V_{b 0}\left(\mathrm{v}_{\tau_{b}^{*}}^{B^{H}}+1\right)}-\frac{1-\eta}{2 \eta-1} .
$$

Now we must consider $V_{b 0}\left(\mathrm{v}_{\tau_{b}^{*}}^{B^{H}}\right)$ a bit more closely because are $\mathrm{v}_{\tau_{b}^{*}}^{B^{H}}$ and $k_{\tau_{b}^{*}}^{B^{H}}$ are inter-related variables. If at time $\tau_{b}^{*}$, the state of the processes are $\mathrm{v}_{\tau_{b}^{*}}^{B^{H}}$ and $k_{\tau_{b}^{*}}^{B^{H}}$, then $V_{b 0}\left(v_{\tau_{b}^{*}}^{B^{H}}\right)=\left(1-p\left(k_{\tau_{b}^{*}}^{A}\right)\right) V_{s 1}\left(k_{\tau_{b}^{*}}^{B^{H}}\right)$. However, if an aggressive buy limit order enters the book at $B^{H}$ and depletes the sell side, $v_{\tau_{b}^{*}}^{B^{H}}$ increases to $\mathrm{v}_{\tau_{b}^{*}}^{B^{H}}+1$, but $k_{\tau_{b}^{*}}^{B^{H}}$ becomes $k_{\tau_{b}^{*}}^{B^{H}} \pm 1$. The reasoning is as follows.

Recall that $\mathrm{v}_{\tau}^{B^{H}}:=b_{\tau}^{B^{H}}-s_{\tau}^{B^{H}}$ where $b_{\tau}^{B^{H}}$ and $s_{\tau}^{B^{H}}$ denote the number of visible buy and sell orders (those with and without hidden depth) recorded in the LOB at $B^{H}$ at $\tau$, respectively. The current situation is that $\mathrm{v}_{\tau_{b}^{*}}^{B^{H}}<0$ and, thus, $\mathrm{v}_{\tau_{b}^{*}}^{B^{H}}=-s_{\tau_{b}^{*}}^{B^{H}} \equiv$ 
$-\left(s_{\tau_{b}^{*}}^{B^{H} f}+s_{\tau_{b}^{*}}^{B^{H} i}\right)$. Moreover, $k_{\tau_{b}^{*}}^{B^{H}}=\left|s_{\tau_{b}^{*}}^{B^{H} f}\right|-\left|s_{\tau_{b}^{*}}^{B^{H} i}\right|$. If one aggressive buy order enters the book at $B^{H}$, it will execute against the sell order at the front of the queue in the LOB. Irrespective of whether this sell is a full or iceberg order, $\mathrm{v}_{\tau_{b}^{*}}^{B^{H}}$ increases to $-\left(s_{\tau_{b}^{*}}^{B^{H} f}+s_{\tau_{b}^{*}}^{B^{H} i}-1\right)=\mathrm{v}^{B^{H}}+1$. However, if the order at the front of the queue is a full sell order, then $k_{\tau_{b}^{*}}^{B^{H}}$ decreases to $\left|s_{\tau_{b}^{*}}^{B^{H} f}-1\right|-\mid s_{\tau_{b}^{*}}^{B^{H}} i=k_{\tau_{b}^{*}}^{B^{H}}-1$, but if it is an iceberg order, $k_{\tau_{b}^{*}}^{B^{H}}$ increases to $\left|s_{\tau_{b}^{*}}^{B^{H}} f\right|-\left|s_{\tau_{b}^{*}}^{B^{H} i}-1\right|=k_{\tau_{b}^{*}}^{B^{H}}+1$.

Finally, if $\mathrm{v}_{\tau_{b}^{*}}^{B^{H}}$ increases to $\mathrm{v}_{\tau_{b}^{*}}^{B^{H}}+1$, then $k_{\tau_{b}^{*}}^{B^{H}}$ increases to $k_{\tau_{b}^{*}}^{B^{H}}+1$ with probability $(1-\theta) p_{\tau_{b}^{*}}^{B^{H}}+\theta\left(1-p_{\tau_{b}^{*}}^{B^{H}}\right){ }^{8}$ However, since $\mathrm{v}_{\tau_{b}^{*}}^{B^{H}}<0$, his sell order will not get filled with certainty and $p_{\tau_{b}^{*}}^{B^{H}}=1$. Thus, $k_{\tau_{b}^{*}}^{B^{H}}$ increases to $k_{\tau_{b}^{*}}^{B^{H}}+1$ with probability $(1-\theta)$. Similarly, $k_{\tau_{b}^{*}}^{B^{H}}$ decreases to $k_{\tau_{b}^{*}}^{B^{H}}-1$ if $\mathrm{v}_{\tau_{b}^{*}}^{B^{H}}$ increases to $\mathrm{v}_{\tau_{b}^{*}}^{B^{H}}+1$ with probability $\theta$. Therefore,

$$
V_{b 0}\left(\mathrm{v}_{\tau_{b}^{*}}^{B^{H}}+1\right)=\left(1-p\left(k_{\tau_{b}^{*}}^{A}\right)\right)\left[(1-\theta) V_{s 1}\left(k_{\tau_{b}^{*}}^{B^{H}}+1\right)+\theta V_{s 1}\left(k_{\tau_{b}^{*}}^{B^{H}}-1\right)\right]
$$

where $V_{s 1}\left(k_{\tau}^{B^{H}}\right)$ is given by Eq. (A.10).

Replacing for $V_{b 0}\left(\mathrm{v}_{\tau_{b}^{*}}^{B^{H}}+1\right)$ and $V_{b 0}\left(\mathrm{v}_{\tau_{b}^{*}}^{B^{H}}\right)$ in Eq. (B.11) gives

$$
\begin{aligned}
q_{\tau_{b}^{*}}^{B^{H}} & =\frac{\eta-1}{2 \eta-1}+\frac{\beta_{2}}{2 \eta-1}\left(\frac{r+\lambda}{\lambda}-\frac{\alpha_{1} \lambda \eta(1-\eta)}{\alpha_{1}(r+\lambda)-\lambda \eta(1-\eta)}\right) \\
\times & \frac{\frac{1}{\theta}+\frac{1}{1-\theta}\left(\frac{1-\theta}{\theta}\right)^{k_{\tau_{b}^{*}}^{B^{H}}}}{1+\left(\frac{1-\theta}{\theta}\right)^{k_{\tau_{b}^{*}}^{B^{H}}}} \frac{1+\left(\frac{1-\theta}{\theta}\right)^{k_{\tau_{b}^{*}}^{B^{H}}+1}}{(1-\theta) \beta_{2}^{2}\left(\frac{1}{\theta^{2}}+\frac{1}{\theta(1-\theta)}\left(\frac{1-\theta}{\theta}\right)^{k_{\tau_{b}^{*}}^{B^{H}}}\right)+\theta\left(1+\left(\frac{1-\theta}{\theta}\right)^{k_{\tau_{b}^{*}}^{B^{H}}+1}\right)}
\end{aligned}
$$

$\overline{8} \mathrm{v}_{\tau_{b}^{*}}^{B^{H}}$ increases to $\mathrm{v}_{\tau_{b}^{*}}^{B^{H}}+1$ iff a buy order entered the LOB. Hence $P(B)=1$. If the buy executes against what is accurately deemed to be an iceberg sell order, this will reduce the visible representation of hidden depth in the LOB. However, $v_{\tau_{b}^{*}}^{B^{H}}<0$ but he will only sell at some $\tau_{s}$ such that $\mathrm{v}_{\tau_{s}}^{B^{H}}>0$. Therefore, in this case, he favors less hidden depth since this implies that the threshold $v_{\tau_{s}^{*}}^{B^{H}}$ will be reached quicker, strengthening his conviction that his sell order will get filled. This event occurs with probability $\theta\left(1-p_{\tau_{b}^{*}}^{B^{H}}\right)$. On the other hand, $k_{\tau_{b}^{*}}^{B^{H}}$ increases to $k_{\tau_{b}^{*}}^{B^{H}}+1$ if the buy executes against what is inaccurately deemed to be a full order. This occurs with probability $(1-\theta) p_{\tau_{b}^{*}}^{B^{H}}$ 
But since $p_{\tau_{b}^{*}}^{B^{H}}=1$, we must take the limit as $k_{\tau_{b}^{*}}^{B^{H}}$ tends to infinity. Hence

$$
q_{\tau_{b}^{*}}^{B^{H}}=\frac{\eta-1}{2 \eta-1}+\frac{\beta_{2}}{2 \eta-1}\left(\frac{r+\lambda}{\lambda}-\frac{\alpha_{1} \lambda \eta(1-\eta)}{\alpha_{1}(r+\lambda)-\lambda \eta(1-\eta)}\right)\left(\frac{\theta}{(1-\theta) \beta_{2}^{2}+\theta^{3}}\right)
$$

Hence

$$
\mathrm{v}_{\tau_{b}^{*}}^{B^{H}}=\frac{\ln \left(\frac{1-q_{\tau_{b}^{*}}^{B^{H}}}{q_{\tau_{b}^{*}}^{B^{H}}}\right)-\ln \zeta}{\ln \left(\frac{1-\eta}{\eta}\right)},
$$

which is well defined for $0<q_{\tau_{b}^{*}}^{B^{H}}<1$. If $q_{\tau_{b}^{*}}^{B^{H}} \geq 1$, then $v_{\tau_{b}^{*}}^{B^{H}}=+\infty$, and if $q_{\tau_{b}^{*}}^{B^{H}} \leq 0, \mathrm{v}_{\tau_{b}^{*}}^{B^{H}}=-\infty$.

\section{Appendix C: Proof of Proposition 5}

1. Let $P_{k_{\tau}^{B}}(\tau)$ denote the conditional probability that the imbalance between new and iceberg orders at $B^{H}$ is $k_{\tau}^{B^{H}}$ at time $\tau$ (for all $k_{\tau}^{B^{H}} \in Z$ ). When the investor started monitoring the order flow at $B^{H}, k_{\tau_{0}}^{B^{H}}=0$. Therefore, $k_{\tau}^{B^{H}}$ could only have been reached if a jump occurred before $\tau$. Hence, $P_{k^{B}}{ }^{H}(\tau)$ is the convolution of the probability that the imbalance was at $k_{\tau}^{B^{H}}+1$ at some time $t<\tau$ or at $k_{\tau}^{B^{H}}-1$ at time $t$, where $t$ is the time at which the last jump occurred. Recall that the arrival of order to the limit order book follows a Poisson process with parameter $\lambda$, then

$$
\begin{gathered}
P_{k_{\tau}^{B} H}(\tau)=\int_{\tau_{0}}^{\tau} \lambda e^{-\lambda(\tau-t)}\left(q_{1}\left(k_{\tau}^{B^{H}}-1\right) P_{k_{\tau}^{B}{ }^{H}-1}(t)\right. \\
\left.+q_{2}\left(k_{\tau}^{B^{H}}+1\right) P_{k_{\tau}^{B}{ }^{H}+1}(t)\right) d t
\end{gathered}
$$

such that $q_{1}\left(k_{\tau}^{B^{H}}-1\right)$ is the probability of reaching $k_{\tau}^{B^{H}}$ from $k_{\tau}^{B^{H}}-1$ and $q_{2}\left(k_{\tau}^{B^{H}}+1\right)$ is the probability of reaching $k_{\tau}^{B^{H}}$ from $k_{\tau}^{B^{H}}+1$.

Taking the Laplace transform of $P_{k_{T}^{B}}(\tau),(\mathrm{C} .1)$ gives the following homogeneous difference equation (cf. Feller 1971)

$\lambda q_{2}\left(k_{\tau}^{B^{H}}+1\right) \mathcal{L}_{k_{\tau}^{B}{ }^{H}+1}(s)-(\lambda+s) \mathcal{L}_{k_{\tau}^{B}}(s)+\lambda q_{1}\left(k_{\tau}^{B^{H}}-1\right) \mathcal{L}_{k_{\tau}^{B}{ }^{H}-1}(s)=0$

where $\mathcal{L}_{k_{\tau}^{B}}(s)$ denotes the Laplace transform of $P_{k_{\tau}^{B}}(\tau)$.

Equation (C.2) has a general solution of the form

$$
\mathcal{L}_{k_{\tau}^{B}}{ }^{H}(s)=L_{1} \kappa_{1}^{k_{\tau}^{B^{H}}}+L_{2} \kappa_{2}^{k_{\tau}^{B^{H}}}
$$


where

$$
\kappa_{1}=\frac{\lambda+s-\sqrt{(\lambda+s)^{2}-4 \lambda^{2} q_{1}\left(k_{\tau}^{B^{H}}-1\right) q_{2}\left(k_{\tau}^{B^{H}}+1\right)}}{2 \lambda q_{2}\left(k_{\tau}^{B^{H}}+1\right)}
$$

and

$$
\kappa_{2}=\frac{q_{1}\left(k_{\tau}^{B^{H}}-1\right)}{q_{2}\left(k_{\tau}^{B^{H}}+1\right)} \kappa_{1}^{-1}
$$

are the roots of the characteristic equation of (C.2).

Assume $k_{\tau}^{B^{H}}>0$. Then as $s \rightarrow \infty, \kappa_{1} \rightarrow 0$. It must be true that $\mathcal{L}_{k_{\tau}^{B}}(s)$ is bounded as $s \rightarrow \infty$. To ensure this is satisfied, we must set $L_{2}=0$. Then

$$
\mathcal{L}_{k_{\tau}^{B}}(s)=L_{1} \kappa_{1}^{k_{\tau}^{B^{H}}} \equiv \mathcal{L}_{0}(s) \kappa_{1}^{k_{\tau}^{B^{H}}}
$$

However, for $k_{\tau}^{B^{H}} \leq 0$, we must have that $L_{1}=0$ so that $\mathcal{L}_{k_{\tau}^{B}}(s)$ is bounded as $s \rightarrow \infty$. Thus, for $k_{\tau}^{B^{H}} \leq 0$

$$
\mathcal{L}_{k_{\tau}^{B} H}(s)=\left(\frac{q_{1}\left(k_{\tau}^{B^{H}}-1\right)}{q_{2}\left(k_{\tau}^{B^{H}}+1\right)}\right)^{k_{\tau}^{B^{H}}} \mathcal{L}_{0}(s) \kappa_{1}^{-k_{\tau}^{B^{H}}} .
$$

Now, if at time $\tau$, the state is $k_{\tau}^{B^{H}}$, the first passage time through $k_{\tau}^{B^{H}}$ must have occurred at some time, say $\tau^{\prime} \leq \tau$. The conditional probability of reaching state $k_{\tau}^{B^{H}}$ again at time $\tau$ is given by (cf. Thijssen et al. 2006)

$$
P_{k_{\tau}^{B} H}(\tau)=\int_{\tau_{0}}^{\tau} f_{k_{\tau}^{B} H}\left(\tau^{\prime}\right) P_{0}\left(\tau-\tau^{\prime}\right) d \tau^{\prime}
$$

where $P_{0}\left(\tau-\tau^{\prime}\right)$ denotes the probability of being at state 0 at time $\tau-\tau^{\prime}$ and $f_{k_{\tau}^{B^{H}}}\left(\tau^{\prime}\right)$ is the probability of a first passage time through $k_{\tau}^{B^{H}}$ at time $\tau^{\prime}$. Equation (C.8) is actually the convolution of the $f_{k_{\tau}^{B}}\left(\tau^{\prime}\right)$ and $P_{0}\left(\tau-\tau^{\prime}\right)$, and the Laplace transform of a convolution of two functions is simply the product of the Laplace transforms of the individual functions (Feller 1971). Therefore, the Laplace transform of (C.8) is given by

$$
\mathcal{L}\left(P_{k_{\tau}^{B} H}(\tau)\right)=\mathcal{L}\left(f_{k_{\tau}^{B} H}\left(\tau^{\prime}\right)\right) \mathcal{L}_{0}(s)
$$

But $\mathcal{L}\left(P_{k_{\tau}^{B} H}(\tau)\right) \equiv \mathcal{L}_{k_{\tau}^{B}{ }^{H}}(s)$. Thus, when $k_{\tau}^{B^{H}}>0$, from Eq. (C.6),

$$
\mathcal{L}\left(f_{k_{\tau}^{B} H}\left(\tau^{\prime}\right)\right)=\kappa_{1}^{k_{\tau}^{B^{H}}}
$$


and from Eq. (C.7), when $k_{\tau}^{B^{H}} \leq 0$,

$$
\mathcal{L}\left(f_{k_{\tau}^{B}}\left(\tau^{\prime}\right)\right)=\left(\frac{q_{1}\left(k_{\tau}^{B^{H}}-1\right)}{q_{2}\left(k_{\tau}^{B^{H}}+1\right)}\right)^{k_{\tau}^{B^{H}}} \kappa_{1}^{-k_{\tau}^{B^{H}}} .
$$

Now for $k_{\tau}^{B^{H}}>0$

$$
\begin{gathered}
f_{k_{\tau}^{B}{ }^{H}}\left(\tau^{\prime}\right)=\mathcal{L}^{-1}\left(\kappa_{1}^{k_{\tau}^{B^{H}}}\right) \\
=\left(\frac{q_{1}\left(k_{\tau}^{B^{H}}-1\right)}{q_{2}\left(k_{\tau}^{B^{H}}+1\right)}\right)^{k_{\tau}^{B^{H}} / 2} \mathcal{L}^{-1}\left(\left(\hat{s}-\sqrt{\hat{s}^{2}-1}\right)^{k_{\tau}^{B^{H}}}\right) \\
\text { for } \hat{s}=(\lambda+s) /\left(2 \lambda \sqrt{q_{1}\left(k_{\tau}^{B^{H}}-1\right) q_{2}\left(k_{\tau}^{B^{H}}+1\right)}\right) \text { and } \\
f_{k_{\tau}^{B}{ }^{H}}\left(\tau^{\prime}\right)=\left(\frac{q_{1}\left(k_{\tau}^{B^{H}}-1\right)}{q_{2}\left(k_{\tau}^{B^{H}}+1\right)}\right)^{k_{\tau}^{B^{H}} / 2} \mathcal{L}^{-1}\left(\left(\hat{s}-\sqrt{\hat{s}^{2}-1}\right)^{-k_{\tau}^{B^{H}}}\right),
\end{gathered}
$$

for $k_{\tau}^{B^{H}} \leq 0$.

From Feller (1971) (page 437),

$$
\mathcal{L}^{-1}\left(\left(\frac{s}{y}-\sqrt{\left(\frac{s}{y}\right)^{2}-1}\right)^{k_{\tau}^{B^{H}}}\right)=\frac{k_{\tau}^{B^{H}}}{\tau^{\prime}} I_{k_{\tau}^{B}}\left(y \tau^{\prime}\right)
$$

and

$$
\mathcal{L}^{-1}\left(\left(s+x-\sqrt{(s+x)^{2}-1}\right)^{k_{\tau}^{B^{H}}}\right)=e^{-\tau^{\prime} x} \frac{k_{\tau}^{B^{H}}}{\tau^{\prime}} I_{k^{B}{ }^{H}}\left(\tau^{\prime}\right),
$$

where $I_{k}(x)$ is the modified Bessel function with parameter $k$. Applying these results gives

$\mathcal{L}^{-1}\left(\left(\hat{s}-\sqrt{\hat{s}^{2}-1}\right)^{k_{\tau}^{B^{H}}}\right)=e^{-\lambda \tau^{\prime}} \frac{k_{\tau}^{B^{H}}}{\tau^{\prime}} I_{k_{\tau}^{B^{H}}}\left(2 \lambda \sqrt{q_{1}\left(k_{\tau}^{B^{H}}-1\right) q_{2}\left(k_{\tau}^{B^{H}}+1\right)} \tau^{\prime}\right)$. 
Substituting into Eqs. (C.12) and (C.13) gives

$$
\begin{aligned}
f_{k_{\tau}^{B}}{ }^{H}\left(\tau^{\prime}\right)= & e^{-\lambda \tau^{\prime}}\left(\frac{q_{1}\left(k_{\tau}^{B^{H}}-1\right)}{q_{2}\left(k_{\tau}^{B^{H}}+1\right)}\right)^{k_{\tau}^{B^{H}} / 2} \\
& \times \frac{k_{\tau}^{B^{H}}}{\tau^{\prime}} I_{k_{\tau}^{B^{H}}}\left(2 \lambda \sqrt{q_{1}\left(k_{\tau}^{B^{H}}-1\right) q_{2}\left(k_{\tau}^{B^{H}}+1\right)} \tau^{\prime}\right)
\end{aligned}
$$

for $k_{\tau}^{B^{H}}>0$, and

$$
\begin{aligned}
f_{k_{\tau}^{B} H}\left(\tau^{\prime}\right)= & -e^{-\lambda \tau^{\prime}}\left(\frac{q_{1}\left(k_{\tau}^{B^{H}}-1\right)}{q_{2}\left(k_{\tau}^{B^{H}}+1\right)}\right)^{k_{\tau}^{B^{H}} / 2} \\
& \times \frac{k_{\tau}^{B^{H}}}{\tau^{\prime}} I_{-k_{\tau}^{B} H}\left(2 \lambda \sqrt{q_{1}\left(k_{\tau}^{B^{H}}-1\right) q_{2}\left(k_{\tau}^{B^{H}}+1\right)} \tau^{\prime}\right)
\end{aligned}
$$

for $k_{\tau}^{B^{H}} \leq 0$.

Returning to $q_{1}\left(k_{\tau}^{B^{H}}-1\right)$ and $q_{2}\left(k_{\tau}^{B^{H}}+1\right)$. These probabilities take different forms depending on whether $\mathrm{v}_{\tau}^{B^{H}}>0$ or $\mathrm{v}_{\tau}^{B^{H}} \leq 0$. Since at $\tau_{s}^{*}, \mathrm{v}_{\tau_{s}^{*}}^{B^{H}}>0$, we need only consider the case for $\mathrm{v}_{\tau}^{B^{H}}>0$.

If $\mathbf{v}_{\tau}^{B^{H}}>0$, buy orders prevail at $B^{H}$ and the probability of reaching $k_{\tau}^{B^{H}}$ from $k_{\tau}^{B^{H}}-1$ is given by

$$
\begin{aligned}
q_{1}\left(k_{\tau}^{B^{H}}-1\right) & =p\left(k_{\tau}^{B^{H}}-1\right) \theta+\left(1-p\left(k_{\tau}^{B^{H}}-1\right)\right)(1-\theta) \\
& =\frac{\theta^{k^{B^{H}}}+(1-\theta)^{k_{\tau}^{B^{H}}}}{\theta^{k_{\tau}^{B^{H}}-1}+(1-\theta)^{k_{\tau}^{B^{H}}-1}}
\end{aligned}
$$

(from Appendix B), and the probability of reaching $k_{\tau}^{B^{H}}$ from $k_{\tau}^{B^{H}}+1$ is

$$
\begin{aligned}
& q_{2}\left(k_{\tau}^{B^{H}}+1\right)=\theta\left(1-p\left(k_{\tau}^{B^{H}}+1\right)\right)+(1-\theta) p\left(k_{\tau}^{B^{H}}+1\right) \\
&=\theta(1-\theta) \frac{\theta^{k^{B^{H}}}-2}{\theta^{k_{\tau}^{B^{H}}}-1}+(1-\theta)^{k_{\tau}^{B^{H}}}-2 \\
&
\end{aligned}
$$


2. The proof that

$$
\begin{aligned}
f_{\mathrm{v}_{\tau_{b}^{*}}^{B^{H}}}\left(\tau_{b}^{*}\right)= & \left(\frac{\hat{q}_{1}\left(\mathrm{v}_{\tau_{b}^{*}}^{B^{H}}-1\right)}{\hat{q}_{2}\left(\mathrm{v}_{\tau_{b}^{*}}^{B^{H}}+1\right)}\right)^{\mathrm{v}_{\tau_{b}^{B^{*}}}^{B^{H}} / 2} \\
& \times \frac{\left|\mathrm{v}_{\tau_{b}^{*}}^{B^{H}}\right|}{\tau_{b}^{*}} I_{\left|\mathrm{v}_{\tau_{b}^{*}}^{B^{H}}\right|}\left(2 \lambda \sqrt{\hat{q}_{1}\left(\mathrm{v}_{\tau_{b}^{*}}^{B^{H}}-1\right) \hat{q}_{2}\left(\mathrm{v}_{\tau_{b}^{*}}^{B^{H}}+1\right)}\right) e^{-\lambda \tau_{b}^{*}},
\end{aligned}
$$

where $\hat{q}_{1}\left(\mathrm{v}_{\tau_{b}^{*}}^{B^{H}}-1\right)$ and $\hat{q}_{2}\left(\mathrm{v}_{\tau_{b}^{*}}^{B^{H}}+1\right)$ denote the respective probabilities of reaching $\mathrm{v}_{\tau_{b}^{*}}^{B^{H}}$ from $\mathrm{v}_{\tau_{b}^{*}}^{B^{H}}-1$ and $\mathrm{v}_{\tau_{b}^{*}}^{B^{H}}+1$, follows similarly.

However, at $\tau_{b}^{*}, \mathrm{v}_{\tau_{b}^{*}}^{B^{H}}<0$. Thus,

$$
\begin{aligned}
& \hat{q}_{1}\left(\mathrm{v}_{\tau_{b}^{*}}^{B^{H}}-1\right)=\eta\left(1-q\left(\mathrm{v}_{\tau_{b}^{*}}^{B^{H}}-1\right)\right)+(1-\eta) q\left(\mathrm{v}_{\tau_{b}^{*}}^{B^{H}}-1\right) \\
& =\eta(1-\eta) \frac{\eta^{\mathrm{v}_{\tau_{b}^{*}}^{B^{H}}-2}+\zeta(1-\eta)^{\mathrm{v}_{\tau_{b}^{*}}^{B^{H}}-2}}{\eta^{\mathrm{v}_{\tau_{b}^{*}}^{B^{H}}-1}+\zeta(1-\eta)^{\mathrm{v}_{\tau_{b}^{*}}^{B^{H}}-1}}
\end{aligned}
$$

and

$$
\begin{aligned}
\hat{q}_{2}\left(\mathrm{v}_{\tau_{b}^{*}}^{B^{H}}+1\right) & =\eta q\left(\mathrm{v}_{\tau_{b}^{*}}^{B^{H}}+1\right)+(1-\eta)\left(1-q\left(\mathrm{v}_{\tau_{b}^{*}}^{B^{H}}+1\right)\right) \\
& =\frac{\eta^{\mathrm{v}_{b}^{*}}+\zeta(1-\eta)^{B_{\tau_{b}^{*}}^{*}}}{\eta^{\mathrm{v}_{\tau_{b}^{*}}^{B^{H}}-1}+\zeta(1-\eta)^{\mathrm{v}_{\tau_{b}^{*}}^{B^{H}}-1}}
\end{aligned}
$$

(cf. Appendix C).

\section{References}

Aitken, M., Berkman, H., Mak, D.: The use of undisclosed limit orders on the Australian stock exchange. J Bank Finance 25(8), 1589-1603 (2001)

Anand, A., Weaver, D.: Can order exposure be mandated? J Financ Markets 7(4), 405-426 (2004)

Bessembinder, H., Panayides, M., Venkatamaran, K.: Hidden liquidity: an analysis of order exposure strategies in electronic stock markets. J Financ Econ 94(3), 361-383 (2009)

Boulatov, A., George, T.: Hidden and displayed liquidity in securities markets with informed liquidity providers. Rev Financ Stud 26(8), 2095-2137 (2013)

Buti, S., Rindi, B.: Undisclosed orders and optimal submission strategies in a limit order market. J Financ Econ 109(3), 797-812 (2013)

Buti, S., Rindi, B., Werner, I.: Dark pool trading strategies, market quality, and welfare. J Financ Econ 124(2), 244-265 (2017) 
Delaney, L., Thijssen, J.: The impact of voluntary disclosure on a firm's investment policy. Eur J Oper Res 242(1), 232-242 (2015)

DeWinne, R., D’Hondt, C.: Hide-and-seek in the market: placing and detecting hidden orders. Rev Finance 11(4), 663-692 (2007)

Dixit, Q., Pindyck, R.: Investment Under Uncertainty. Princeton: Princeton University Press (1994)

Feller, W.: An Introduction to Probability Theory and Its Applications, vol. 2, 2nd edn. London: Wiley (1971)

Flor, C.R., Hansen, S.L.: Technological advances and the decision to invest. Ann Finance 9, 383-420 (2013)

Frey, S., Sandås, P.: The Impact of Iceberg Orders in Limit Order Books. Working Paper, available at SSRN: http://ssrn.com/abstract=1108485 (2009)

Gutierrez, O., Ruiz-Aliseda, F.: Real options with unknown-date events. Ann Finance 7, 171-198 (2011)

Harris, L.: Does a Large Minimum Price Variation Encourage Order Exposure? Working Paper. http:// www-bcf.usc.edu/ lharris/ACROBAT/HIDDEN.PDF (1996)

Hasbrouck, J., Saar, G.: Technology and liquidity provision: the blurring of traditional definitions. J Financ Markets 12(2), 143-172 (2009)

Moinas, S.: Hidden Limit Orders and Liquidity in Limit Order Markets. Working paper, Toulouse Business School (2010)

Thijssen, J., Huisman, K., Kort, P.: The effect of information streams on capital budgeting decisions. Eur J Oper Res 157(3), 759-774 (2004)

Thijssen, J., Huisman, K., Kort, P.: The effects of information on strategic investment and welfare. Econ Theor 28(2), 399-424 (2006)

Tuttle, L.: Hidden Orders, Trading Costs and Information. Working paper, available at SSRN: http://ssrn. com/abstract $=676019(2006)$ 